\title{
Evolution of Mediterranean Sea water properties under climate change scenarios in the Med-CORDEX ensemble
}

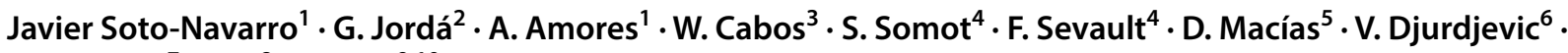

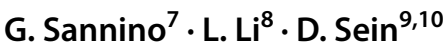

Received: 14 July 2019 / Accepted: 23 December 2019

(c) Springer-Verlag GmbH Germany, part of Springer Nature 2020

\begin{abstract}
Twenty-first century projections for the Mediterranean water properties have been analyzed using the largest ensemble of regional climate models (RCMs) available up to now, the Med-CORDEX ensemble. It is comprised by 25 simulations, 10 historical and 15 scenario projections, from which 11 are ocean-atmosphere coupled runs and 4 are ocean forced simulations. Three different emissions scenarios are considered: RCP8.5, RCP4.5 and RCP2.6. All the simulations agree in projecting a warming across the entire Mediterranean basin by the end of the century as a result of the decrease of heat losses to the atmosphere through the sea surface and an increase in the net heat input through the Strait of Gibraltar. The warming will affect the whole water column with higher anomalies in the upper layer. The temperature change projected by the end of the century ranges between 0.81 and $3.71{ }^{\circ} \mathrm{C}$ in the upper layer $(0-150 \mathrm{~m})$, between 0.82 and $2.97{ }^{\circ} \mathrm{C}$ in the intermediate layer $(150-600 \mathrm{~m})$ and between 0.15 and $0.18{ }^{\circ} \mathrm{C}$ in the deep layer $(600 \mathrm{~m}$-bottom). The intensity of the warming is strongly dependent on the choice of emission scenario and, in second order, on the choice of Global Circulation Model (GCM) used to force the RCM. On the other hand, the local structures reproduced by each simulation are mainly determined by the regional model and not by the scenario or the global model. The salinity also increases in all the simulation due to the increase of the freshwater deficit (i.e. the excess of evaporation over precipitation and river runoff) and the related increase in the net salt transport at the Gibraltar Strait. However, in the upper layer this process can be damped or enhanced depending upon the characteristics of the inflowing waters from the Atlantic. This, in turn, depends on the evolution of salinity in the Northeast Atlantic projected by the GCM. Thus a clear zonal gradient is found in most simulations with large positive salinity anomalies in the eastern basin and a freshening of the upper layer of the western basin in most simulations. The salinity changes projected for the whole basin range between 0 and 0.34 psu in the upper layer, between 0.08 and 0.37 psu in the intermediate layer and between -0.05 and 0.33 in the deep layer. These changes in the temperature and salinity modify in turn the characteristics of the main water masses as the new waters become saltier, warmer and less dense along the twenty-first century. There is a model consensus that the intensity of the deep water formation in the Gulf of Lions is expected to decrease in the future. The rate of decrease remains however very uncertain depending on the scenario and model chosen. At the contrary, there is no model consensus concerning the change in the intensity of the deep water formation in the Adriatic Sea and in the Aegean Sea, although most models also point to a reduction.
\end{abstract}

\section{Introduction}

The Mediterranean Sea is a semi-enclosed basin confined between Southern Europe, the Middle East and Northern Africa, only connected to the global ocean by the narrow Strait of Gibraltar (Fig. 1). The excess of evaporation over precipitation generates a water deficit in the basin that is compensated by a net inflow of Atlantic Waters (AW) through the Strait (Bethoux and Gentili 1999; Mariotti et al. 2002). These relatively fresher and warmer waters are progressively transformed along their path through the

Electronic supplementary material The online version of this article (https://doi.org/10.1007/s00382-019-05105-4) contains supplementary material, which is available to authorized users.

Javier Soto-Navarro

jsoto@imedea.uib-csic.es

Extended author information available on the last page of the article 


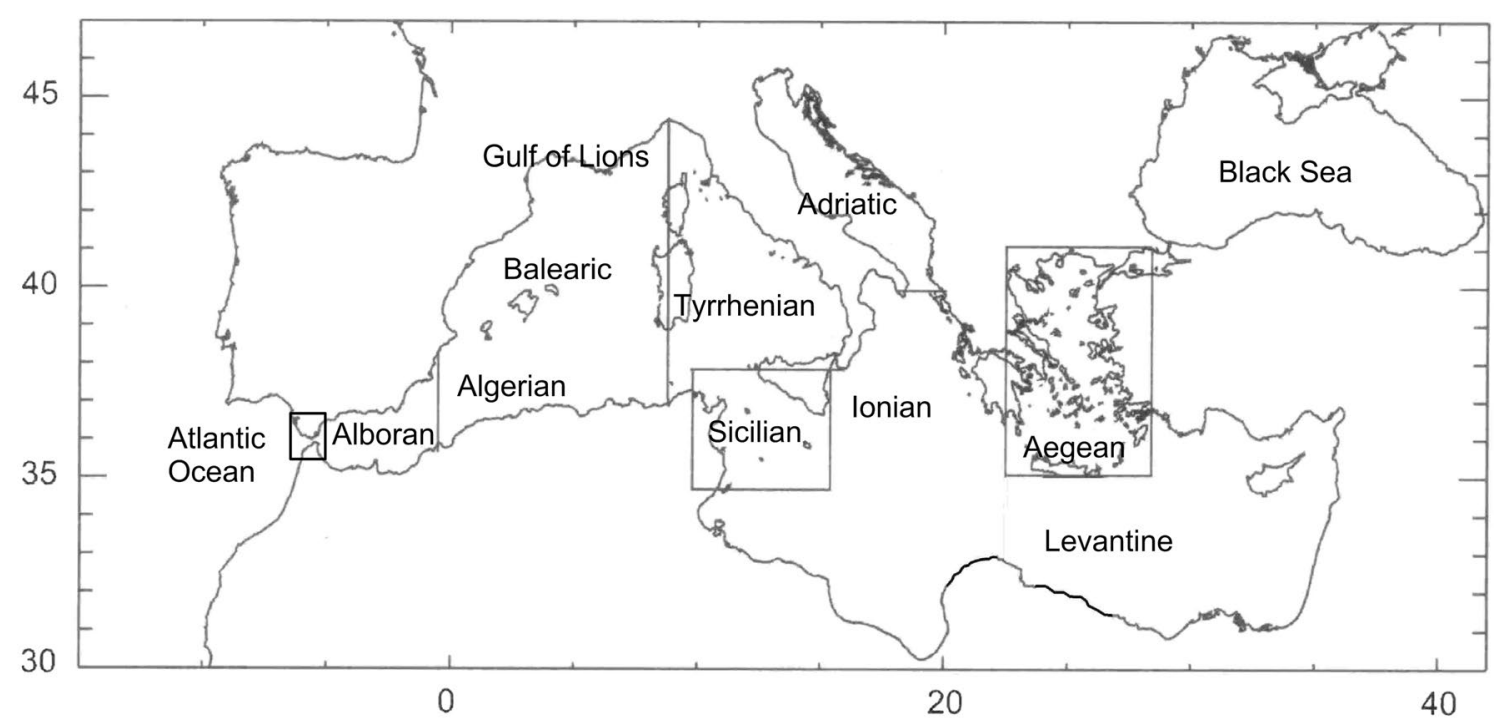

Fig. 1 Map of the Mediterranean Sea basin and sub-basins

basin, becoming the Modified Atlantic Waters (MAW), and eventually sinking to intermediate and deep layers in convective processes triggered by winter cooling. The main core of the intermediate waters is produced in winter in the Levantine basin and hence is known as the Levantine Intermediate Water (LIW). The LIW recirculates westward at depths between 300 and $500 \mathrm{~m}$ towards the Strait of Sicily and finally towards the Strait of Gibraltar, constituting the main thermohaline cell of the basin (Robinson et al. 1991; Demirov and Pinardi 2002; Waldman et al. 2018). Secondary cells appear in the spots where the Mediterranean deep waters are produced. In the Eastern basin, these spots are the Adriatic and the Aegean Seas, where strong winter cooling increases the density of the LIW provoking its sinking to the deeper layer and generating the Eastern Mediterranean Deep Water (EMDW) (Roether and Schlitzer 1991; Roether et al. 1996). In the Western Mediterranean, the deep water formation takes place at the Gulf of Lions in winters when strong heat losses through the sea surface are combined with the preconditioning of the surface and intermediate waters, i.e., waters that have previously increase its salinity by different processes in their path along the basin towards the deep water formation area. This facilitates the convection process and the Western Mediterranean Deep Water (WMDW) is generated (Marshall and Schott 1999; Somot et al. 2018a). This is a very simplified scheme of the so called Mediterranean Thermohaline Circulation (MTHC hereinafter), a feature that makes the Mediterranean basin unique, since it is the only mid-latitude marginal sea where deep convective processes typical for the open ocean and high latitudes take place. For this reason, combined with the fact that a rich mesoscale field is present in the basin including a complex current system and structures like filaments and eddies, the
Mediterranean has been described as a miniature laboratory for climate studies (Bethoux et al. 1999).

As a result of MTHC the average residence time of the basin water masses is around 100 years, way shorter than for the global ocean (Malanotte-Rizzoli et al. 2014). In addition, the Mediterranean is one of the most responsive regions to the climate change, and it has been defined as a primary "hot spot" (Giorgi 2006). Climate change projections point to a warmer and dryer Mediterranean by the end of the twenty-first century, both using global simulations (Giorgi and Lionello 2008; Mariotti et al. 2008; IPCC 2013, 2018), and regional atmosphere simulations (Sanchez-Gomez et al. 2009; Dubois et al. 2012). Due to the complexity of the MTHC and the importance of the mesoscale activity in the basin, to assess how the sea would respond to changes in the atmospheric conditions high resolution ocean climate models are needed (Somot et al. 2008; Li et al. 2012) forced by high resolution atmospheric forcing (Herrmann and Somot 2008) and taking care of the river evolution (Skliris and Lascaratos 2004; Adloff et al. 2015).

In the last decades a strong effort has been carried out to develop and improve regional climatic circulation models for the Mediterranean (Zavatarelli and Mellor 1995; Pinardi and Masetti 2000; Demirov and Pinardi 2002; Fernández et al. 2005; Oddo et al. 2009; Sannino et al. 2009, 2015; Beuvier et al. 2010, 2012; Escudier et al. 2016; Hamon et al. 2016; Waldman et al. 2017; Somot et al. 2018a). In the recent years, the skills of the models to reproduce complex processes as the basin mesoscale dynamics (Escudier et al. 2016), the Eastern Mediterranean Transient (EMT) (Beuvier et al. 2010), the deep water formation in the Gulf of Lions (Somot et al. 2018a) or the exchange through the Strait of Gibraltar (Soto-Navarro et al. 2015) have been satisfactorily 
tested. Indeed, the regional models have been proven as a very useful tool to reproduce and understand many aspects of the present Mediterranean climate that would have been impossible to study from an observational perspective or using global low resolution models.

However, up to now only a few works have dealt with the investigation of future climate projections at regional scale. Thorpe and Bigg (2000) studied the future evolution of the Mediterranean waters outflowing to the Atlantic through the Strait of Gibraltar, finding a reduction in the deep water production of the basin. Somot et al. (2006) performed the first realistic scenario simulation (SRES-A2), projecting a general warming and salinity increase of the whole water column in the basin $\left(+3.1^{\circ} \mathrm{C}\right.$ and +0.48 psu for the surface and $+1.5^{\circ} \mathrm{C}$ and +0.23 psu for the deep layer), and a reduction of $-40 \%$ in the intensity of the MTHC. The future changes in the heat and freshwater budgets were addressed by Sanchez-Gomez et al. (2009) and Dubois et al. (2012) using A1B scenario simulations for the first half of the twenty-first century. Both works agree in expecting an increase of the freshwater deficit and the heat content of the basin by the year 2050. Gualdi et al. (2013), using the same ensemble of coupled simulations, confirmed the previous results and estimated a sea surface warming between +1.5 and $+2{ }^{\circ} \mathrm{C}$ by 2050 under the A1B scenario. A more recent work of Adloff et al. (2015), based on an ensemble of five simulations based on NEMOMED8 model run under three scenarios (A1B, A2 and B1) and using different boundary conditions, found a warming ranging between +1.73 and $+2.97{ }^{\circ} \mathrm{C}$ and a change in the salinity between +0.48 and +0.89 psu by 2100 . The authors conclude that the choice of scenario is the most important element conditioning the warming while the boundary conditions in the Atlantic are more decisive in the evolution of the salinity and the Mediterranean water masses. Macias et al. (2015) studied the projected evolution of primary productivity in the Mediterranean using four simulations ran under RCP 4.5 and RCP 8.5 scenarios. Their results did not show significant net changes at basin scale but showed important variations in the spatial distribution of the productivity areas. The same ensemble of simulations was used by Macias et al. (2018) to study the biochemical response of the Mediterranean to the changes in the freshwater budget. The results showed a high sensitivity of the sea surface salinity to the evolution of the freshwater budget, which evolution is very dependent on the choice of scenario.

The previous works listed were based on a single simulation (Thorpe and Bigg 2000; Somot et al. 2006), an ensemble of 5 multi-model simulations using a single scenario and covering only the first half of the twenty-first century (Gualdi et al. 2013) or an ensemble of multi-scenario simulations using the same model (Adloff et al. 2015; Macias et al. 2015, 2018). Recently, and thanks to the efforts of the different institutions contributing to the Med-CORDEX initiative (https://www.medcordex.eu/; Ruti et al. 2015), coordinated multi-model and multi-scenario studies of the Mediterranean are possible. For example, very recently, Darmaraki et al. (2019) analyzed the evolution of sea surface temperature and marine heat waves (MHW) in the twenty-first century using an ensemble of 17 fully coupled atmosphere-ocean simulations. The ensemble projects stronger and more intense MHW in the future, as a result of the increase of the mean SST. The authors also concluded that the choice of emission scenario became more determining for the MHW characteristics by the second half of the twenty-first century.

In this work we extend and complement previous studies using the Med-CORDEX ensemble to assess the future evolution of the Mediterranean water properties in the whole water column. For the first time, an ensemble of 25 simulations based on six different regional climate models and run under three different emission scenarios has been gathered and analyzed. Our objective is twofold: first, to evaluate the response of the water properties of the Mediterranean Sea under different scenarios of global warming and based on the largest simulation ensemble available until now. Second, to analyze the sensitivity of the projections to the different configurations of the simulations: emission scenario, regional climate model and global model used. The paper is organized as follows: in Sect. 2 the main characteristics of models and simulations are described and the results of the validation for the present climate are analyzed. In Sects. 3 and 4 , the results for the temperature and heat budget and for the salinity and salt budget are presented, respectively. In Sect. 5 we study the evolution the main Mediterranean water masses and the deep convection processes. Finally, the discussion of the results and the main conclusions are presented in Sects. 6 and 7.

\section{Models and simulations}

\subsection{Description of models and simulations}

Simulations from six different Regional Climate Models (RCM) provided by six research institutions member of the Med-CORDEX initiative have been analyzed in this study. The main characteristics of models and simulations are summarized in Table 1 and described in detail in the supplementary material (SM), so here only the main aspects are presented. Five of the RCM are coupled ocean-atmosphere regional climate system models (RCSM) (ROM from AWI, LMDZ-MED from LMD, EBU-POM from UBEL, PROTHEUS from ENEA and CNRM-RCSM4 from CNRM) and one is forced (GETM from JRC). Hereinafter each model will be identified by the name of the institution that provides 


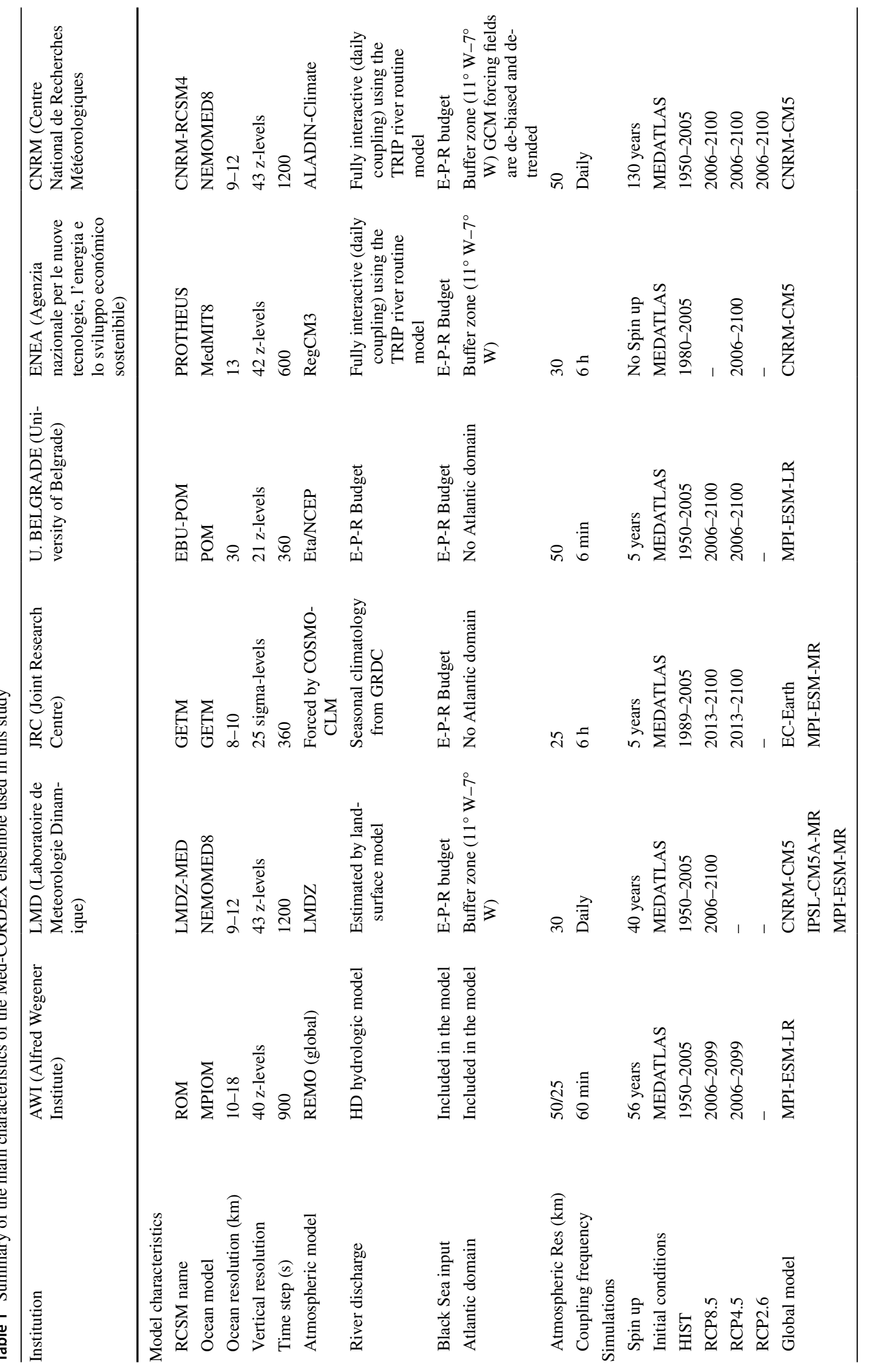




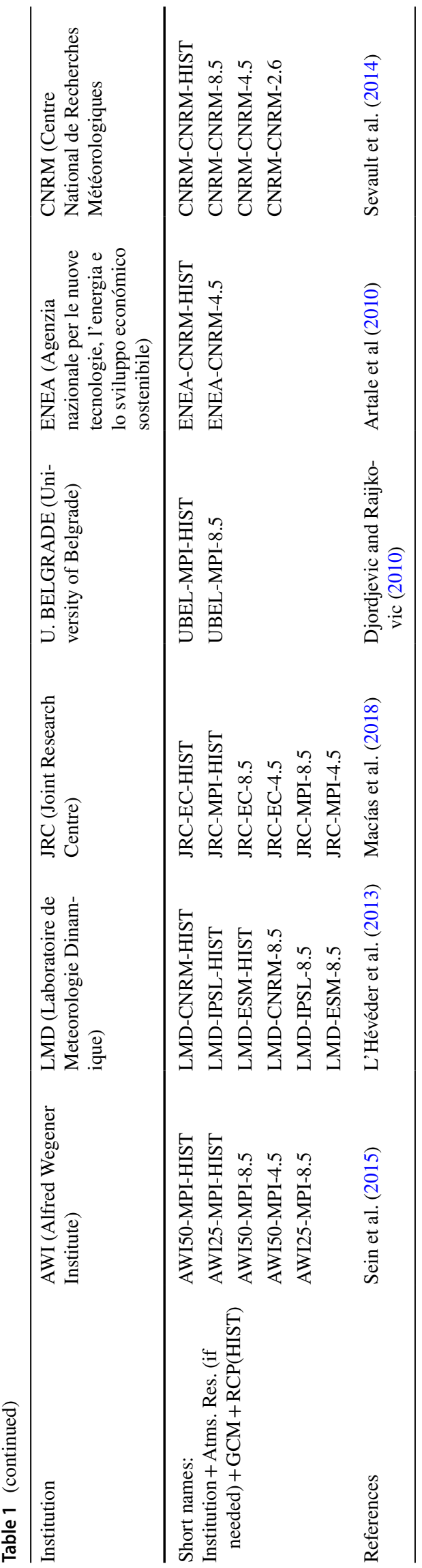

it. The resolution of the ocean models ranges between 8 and $30 \mathrm{~km}$ (eddy-resolving), and between 25 and $50 \mathrm{~km}$ for the atmospheric models. The domains cover the Mediterranean region and a small part of the Atlantic close to the Strait of Gibraltar (except JRC, that don't have Atlantic Domain and AWI that includes a large domain in the Atlantic). The contribution of rivers is explicitly modeled by a hydrologic component in all the models except JRC, which keeps river runoff constant. The Black Sea input is parameterized from the freshwater budget in the Black Sea with the exception of AWI which explicitly solves it.

The ensemble is comprised by a total of 25 simulations: 10 historical runs and 15 twenty-first century projections. The lateral boundary conditions for the atmospheric and ocean components are provided by 5 different Global Climate Models (GCMs). All the projections are run under the Radiative Concentration Pathway (RCP) socio - economic scenarios (Meinshausen et al. 2011). Among them, two main emission scenarios are considered: RCP 8.5 (9 simulations) and RCP 4.5 (5 simulations). Only one simulation has been run under the most optimistic RCP 2.6 scenario, the closest to the Paris agreement targets. Taking into account the large number of simulations that are being analyzed, it is important to clarify the criteria used for their identification along the text. Each simulation is noted by three elements: RCM institution name, GCM name and RCP scenario. Additionally, AWI simulations include the resolution of the atmospheric model in the institution name. Therefore, AWI50-MPI-8.5 is the simulation run by AWI, with $50 \mathrm{~km}$ atmospheric resolution, using the MPI GCM and under RCP8.5 scenario. When the results discussed concern a family of simulations (i.e., all the simulations run by the same institution) they will be noted using only the institution name (AWIs, LMDs, JRCs, or CNRMs). The specific details of each simulation are summarized in Table 1.

\subsection{Present climate validation}

Before starting the analysis of the projections and to correctly understand their range of accuracy it is necessary to assess the ability of the models to reproduce the ocean climate statistics during the past decades. In particular we focus on the SST and SSS, as well as on the deeper thermohaline properties of the Mediterranean waters. Considering that, by construction, the simulations cannot be expected to follow the chronology of past atmospheric states (i.e.: no data assimilation is involved), we evaluate their mean state and the spatio-temporal characteristics of the variability. In particular we analyze the amplitude of the seasonal cycle, the magnitude of the interannual variability and the trends of temperature and salinity at the surface $(0-150 \mathrm{~m})$, intermediate (150-600 m) and deep (600 m-bottom) layers. The goal of this evaluation is to characterize the model behavior in 
order to evaluate their accuracy in the representation of the future climate. In the case of the trend analysis, more than to evaluate climatic signals, the objective is to identify if there are any simulation showing anomalous drifts. The detailed explanation of the models drifts or bias is out of the scope of this study. More exhaustive validation of the different simulations can be found in the references cited in Table 1. It is worth to point out that historical and control runs are only available after 1950 because the GCM files required to force the RCMs were not stored at the CMIP5 database.

For the evaluation, we use as reference two state-of-theart reanalysis products: one based on dynamical interpolation from the Copernicus Marine Environment Monitoring Service (CMEMS; https://www.marine.copernicus.eu) (Simoncelli et al. 2014) and another based on statistical interpolation (MEDHYMAP2.2) (Jordà et al. 2017). The historical runs have been compared with the reference products over their common periods (1987-2005). The average results of the whole basin are outlined in Tables 2 and 3. First we analyze the seasonal cycle, which is a good indicator of the skills of the models reproducing air-sea interactions (for the temperature), and the circulation patterns in the upper layer (for the salinity). For the amplitude of the seasonal cycle, only the surface and upper layers have been considered because no significant seasonality is observed in the deeper layers. The SST seasonal amplitudes of the reanalyses are $10.6{ }^{\circ} \mathrm{C}$ in CMEMS-REAN and $11.6{ }^{\circ} \mathrm{C}$ in MEDHYMAP2.2. All the simulations show smaller amplitudes, between $8.4{ }^{\circ} \mathrm{C}$ (AWI50-HIST) and 10.3 (CNRMHIST) (Table 2). This bias is somehow corrected when the first $150 \mathrm{~m}$ are considered. In the upper layer most of the simulations show amplitudes ranging from 3.3 to $3.6^{\circ} \mathrm{C}$, very close to those of the reanalysis $\left(3.7^{\circ} \mathrm{C}\right.$ for CMEMSREAN and $3.2^{\circ} \mathrm{C}$ for MEDHYMAP2.2), only JRCs simulations $\left(4.5^{\circ} \mathrm{C}\right)$ and UBEL-MPI-HIST $\left(2.7^{\circ} \mathrm{C}\right)$ are out from the observed range. For the SSS, the seasonal cycle amplitudes of the reanalyses are 0.51 psu for CMEMS-REAN and 0.42 psu for MEDHYMAP2.2 (Table 3). AWIs, UBEL-MPIHIST and JRC-EC-HIST simulations show smaller amplitudes $(0.22,0.27$ and 0.38 psu, respectively), while in LMDs and CNRM-CNRM-HIST simulations the amplitudes are higher (between 0.67 and 0.84 psu). Only JRC-MPI-HIST (0.41 psu) and ENEA-CNRM-HIST (0.45 psu) show SSS amplitudes similar to those of the reanalyses. As for the temperature, when the whole upper layer is considered the bias is reduced. All the simulations show an amplitude of the seasonal cycle within the range of the reanalyses $(0.15-0.24$ psu), with the exception of UBEL-MPI HIST which has an amplitude of 0.10 psu. The phase of the cycle agrees well in models and reanalyses, with maximum in September and July for $\mathrm{T}$ and $\mathrm{S}$ respectively and minimum in March for both variables in the surface and upper layers (not shown).

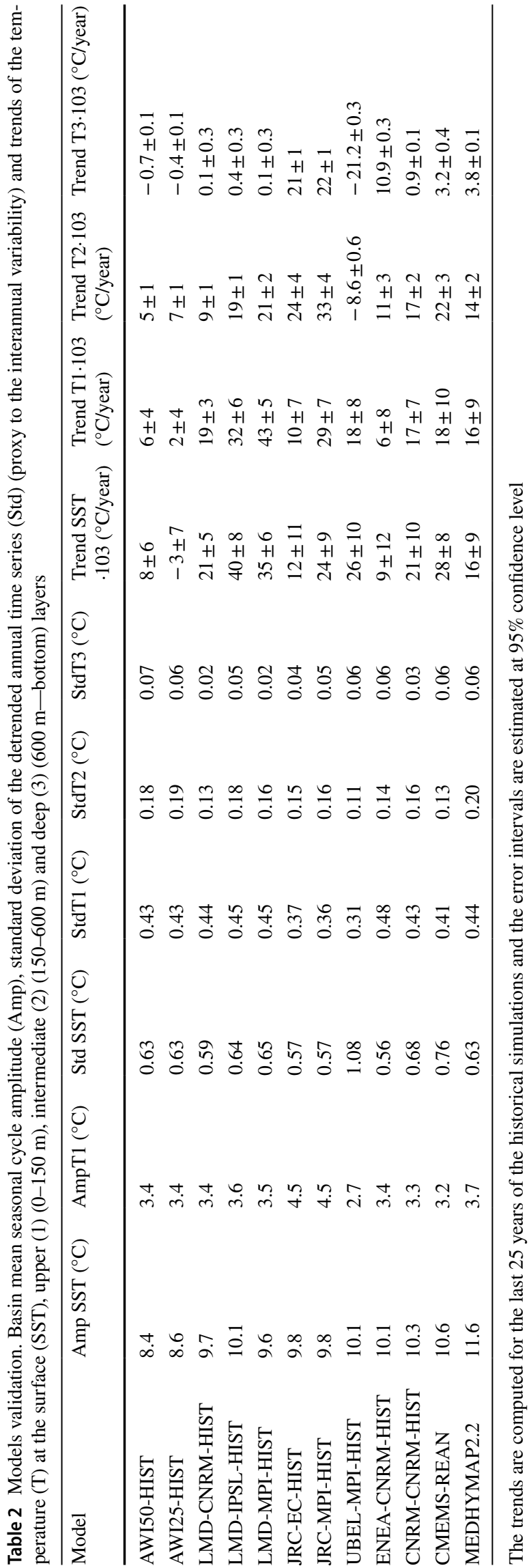




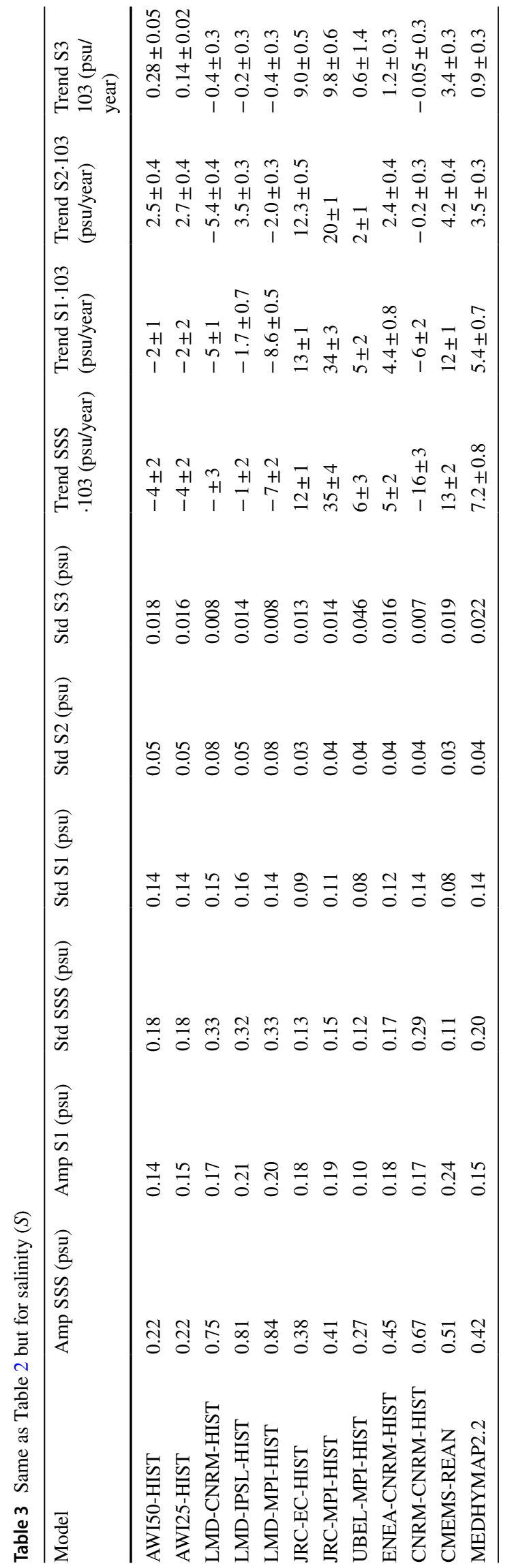

The magnitude of the interannual variability has been quantified using the standard deviation of the detrended annual anomalies. The SST variability is slightly smaller than the reanalysis data $\left(0.76^{\circ} \mathrm{C}\right.$ in CMEMS-REAM and $0.63{ }^{\circ} \mathrm{C}$ in MEDHYMAP2.2) in JRCs $\left(0.57^{\circ} \mathrm{C}\right)$, ENEACNRM-HIST $\left(0.56^{\circ} \mathrm{C}\right)$ and LMD-CNRM-HIST $\left(0.59^{\circ} \mathrm{C}\right)$ simulations (Table 2). For UBEL-MPI-HIST the variability is very high $\left(1.08{ }^{\circ} \mathrm{C}\right)$, while the rest of the simulations are in the range of the reanalyses. In the upper and intermediate layers, simulation and reanalyses show similar values (Table 2). In the first $150 \mathrm{~m}$ most simulations show values close to the observations $\left(0.41-0.44{ }^{\circ} \mathrm{C}\right)$. JRCs SST have slightly smaller variability $\left(0.36-0.37^{\circ} \mathrm{C}\right)$ and UBEL-MPIHIST simulation is the one showing the largest discrepancy $\left(0.31^{\circ} \mathrm{C}\right)$. It is interesting to note that this simulation has a strong positive bias in the SST that is drastically reduced when the whole upper layer is considered. For the intermediate layer all the simulations fall in the reanalyses range $\left(0.13-0.20^{\circ} \mathrm{C}\right)$ except the UBEL-MPI-HIST run $\left(0.11^{\circ} \mathrm{C}\right)$. In the deeper layer, the reanalyses have the same value $0.06{ }^{\circ} \mathrm{C}$, LMD-CNMR-HIST, LMD-MPI-HIST and CNRM-CNRM-HIST simulations show a smaller variability $\left(0.02-0.03{ }^{\circ} \mathrm{C}\right)$ while for the rest the values are very close to both reanalyses.

The standard deviation of the interannual variability of the SSS in the reanalyses is 0.11 psu for CMEMS-REAN and 0.20 for MEDHYMAP2.2. All the simulations have values within this range, except LMDs which show higher standard deviation values $\left(0.32-0.33{ }^{\circ} \mathrm{C}\right)$ (Table 3$)$. In the first two layers of the water column, the salinity interannual variability does not show very significant discrepancies between simulations and reanalyses. In the upper layer the variability ranges between 0.08 and 0.14 psu in the reanalyses while ranging between 0.08 and 0.16 psu in the models. In the intermediate layer, all simulations oscillate between 0.03 and 0.05 , in good agreement with the reanalyses, except for LMD-CNRM-HIST and LMD-MPI-HIST, both with values of 0.08 psu. Higher differences are found in the deepest layer, where the values for CMEMS and MEDHYMAP are 0.022 and 0.019 psu respectively while for some simulations (LMD-CNRM-HIST, LMD-MPI-HIST and CNRM-CNRMHIST) standard deviation values are one order of magnitude lower $(0.008 \mathrm{psu})$ and for UBEL-MPI-HIST is more than double $(0.046 \mathrm{psu})$ the standard deviation of the reanalyses.

Finally, we assess the temperature and salinity trends. It has to be noted that decadal variations may affect the 25-year trend estimates. As the historical simulations are not constraint to follow the observed chronology, we cannot expect a perfect match between reanalysed and modeled 25-year trends, especially in the upper layer where the decadal variations are more intense (Macias et al. 2013). Nevertheless, this diagnostic is useful to identify outliers. The basin averaged results are summarized in Tables 2 and 3, and some 
discrepancies are clear between simulations and reanalyses. For the SST the range of trends in the reanalyses (including the uncertainty) is quite large with [7-36] $\times 10^{-3}{ }^{\circ} \mathrm{C} /$ year. The only simulation out of this range is AWI25-MPIHIST, which show a trend of $-3 \pm 7 \times 10^{-3}{ }^{\circ} \mathrm{C} /$ year. LMDIPSL-HIST and LMD-MPI-HIST, with $40 \pm 8 \times 10^{-3}{ }^{\circ} \mathrm{C} /$ year and $35 \pm 6 \times 10^{-3}{ }^{\circ} \mathrm{C} /$ year respectively, are in the upper limit of the reanalyses range (Table 2). For the temperature of the upper layer, LMD-CNRM-HIST, JRC-ECHIST, UBEL-MPI-HIST and CNRM-CNRM-HIST are the only simulations in agreement with the observed range [7-28] $\times 10^{-3}{ }^{\circ} \mathrm{C} /$ year. The rest show very low (AWI50(25)MPI-HIST, ENEA-CNRM-HIST simulations) or very high values (LMD-MPI-HIST, LMD-IPSL-HIST, JRC-MPIHIST simulations) with respect to the observationally-based ones. In the intermediate layer the differences between simulations and reanalyses are not that pronounced, although still quite important for some simulations. In particular for UBEL-MPI-HIST, which is the only simulation with negative trend in this layer $\left(-8.6 \times 10^{-3}{ }^{\circ} \mathrm{C} /\right.$ year $)$ and JRC-MPIHIST which shows $33 \pm 4 \times 10^{-3}{ }^{\circ} \mathrm{C} /$ year, well outside the observational range [12-25] $\times 10^{-3}{ }^{\circ} \mathrm{C} /$ year. In the deep layer the largest discrepancies are found. All simulations show values that are very far from those obtained from the reanalyses [2.8-3.9] $\times 10^{-3}{ }^{\circ} \mathrm{C} /$ year. AWIs, LMDs and CNRM simulations show very low values, between $-0.7 \times 10^{-3}$ and $0.9 \times 10^{-3}{ }^{\circ} \mathrm{C} /$ year while higher trends are shown by ENEA-CNRM-HIST $\left(10 \times 10^{-3}{ }^{\circ} \mathrm{C} /\right.$ year $)$ and JRCs $\left(20 \times 10^{-3}{ }^{\circ} \mathrm{C} /\right.$ year $)$ simulations. As for the intermediate layer, UBEL-MPI-HIST is the only simulation that shows a highly negative trend $\left(-21 \times 10^{-3}{ }^{\circ} \mathrm{C} /\right.$ year $)$.

The salinity trends show even stronger discrepancies between simulations and reanalyses. For the SSS only JRC-EC-HIST trend is inside the observational range [6.4-15] $\times 10^{-3}$ psu/year (Table 3). JRC-MPI-HIST has a higher trend and the rest of the simulations show very low or negative values (reaching $-16 \times 10^{-3} \mathrm{psu} / \mathrm{year}$ in CNRMHIST).In the upper layer both reanalyses product show positive values [4.7-13] $\times 10^{-3}$ psu/year. AWIs, LMDs and CNRM simulations have negative mean trends ([-8 to -2$] \times 10^{-3} \mathrm{psu} /$ year) while ENEA-CNRM-HIST, UBEL-MPI-HIST and JRCs simulations show positive values, the latter reaching $34 \times 10^{-3} \mathrm{psu} / \mathrm{year}$. In the intermediate layer the two reanalyses are in better agreement [3.2-4.6] $\times 10^{-3}$ psu/year. AWIs, LMD-IPSL-HIST, ENEA-CNRM-HIST, and UBEL-MPIHIST simulations also show positive values of the same order ([2-3.5] $\times 10^{-3}$ psu/year). LMD-CNRM-HIST, LMD-MPIHIST and CNRM-CNRM-HIST simulations have negative trends between $-5.4 \times 10^{-3} \mathrm{psu} / \mathrm{year}$ and $-0.2 \times 10^{-3} \mathrm{psu} /$ year. JRCs simulations once again show abnormally high trends in this layer reaching $20 \times 10^{-3}$ psu/year. As in the case of the temperature, the largest discrepancies are found in the deepest layer where most models show values outside the reanalyses range [0.6-3.7] $\times 10^{-3}$ psu/year. AWIs, LMDs, and CNRM simulations show very low trends, between $-0.4 \times 10^{-3} \mathrm{psu} /$ year and $0.3 \times 10^{-3} \mathrm{psu} /$ year, while in JRCs simulations the trends are once more very high in comparison with the rest of simulations and reanalyses $\left(9-9.8 \times 10^{-3} \mathrm{psu} /\right.$ year).

The comparison between models and reanalyses in terms of the spatial patterns of the seasonal cycle amplitude, interannual variability and trends of temperature and salinity is presented in the supplementary material (Figs S1-S14). The results are in the same line than for the basin average, with better agreement between reanalyses and simulations in the upper and intermediate layers, and larger discrepancies in the deep layer. In general, the spatial distribution over the basin of the areas with higher/lower values is satisfactorily reproduced by all the models. However, significant differences are observed for the $\mathrm{T}$ and $\mathrm{S}$ trends values in the intermediate layer and especially in the deep layer for JRCs, ENEA-CNRM-HIST and UBEL-MPI-HIST simulations.

In summary, in the surface and upper layers, the discrepancies between all the simulations and the reanalyses are in the same range of those obtained in previous works. They are mainly attributed to uncertainties in the surface heat and freshwater fluxes (Nabat et al. 2014; Harzallah et al. 2018; Llasses et al. 2018; Darmaraki et al. 2019). In the intermediate and deep layers, the difficulties of the ocean circulation models to reproduce the salinity and temperature trends have also been reported. Llasses et al. (2018) analyzed 14 hindcast simulations from state-of-the-art ocean models and established that present-day regional models can provide reasonable estimates in the surface and upper layers but below $150 \mathrm{~m}$ are less reliable. In our case, the trends obtained for AWIs, LMDs, and CNRMs for the temperature and also for ENEA-CNRM-HIST for the salinity are in the range of variability of the state-ofthe-art models for the Mediterranean. Therefore, the observed biases can be considered a consequence of the models limitations. On the contrary, for JRCs, UBEL-MPI-HIST and ENEA-MPI-HIST (only for temperature) the observed drifts are much higher and maintained during the projection. This makes us think that these runs did not reach a stable stationary state in the intermediate and deep layers. For this reason, they will be treated with caution in the analysis of the projections in those layers. They will be identified in figures and tables and excluded from the ensemble average computations.

\section{Temperature evolution in the twenty-first century}

\subsection{Sea surface temperature}

The anomalies of the Sea Surface Temperature (SST), computed as the difference between the last 25 years of 
the historical runs (1980-2005) and the last 25 years of the projections (2075-2100), are represented in Fig. 2 and summarized in Table 4 (the periods are 15 years long for JRC). In all the simulations the SST increases by the end of the century but the magnitude and, to a lesser extent, the spatial distribution of this warming significantly varies depending on the simulation. The choice of emissions scenario appears to be the most relevant factor in the variation of the SST by the end of the twenty-first century.
The simulations run under RCP 8.5 scenario show an average increase between 2 and $4{ }^{\circ} \mathrm{C}$, while the simulations run under RCP 4.5 and RCP 2.6 scenarios show lower warming (between 0 and $2{ }^{\circ} \mathrm{C}$ ). Moreover, if we focus on model configurations that are run under both RCP4.5 and RCP8.5, we find an average increase of 1.30 and $2.43{ }^{\circ} \mathrm{C}$, respectively. The representation of the spatial Root Mean Square Difference (RMSD) between pairs of simulations

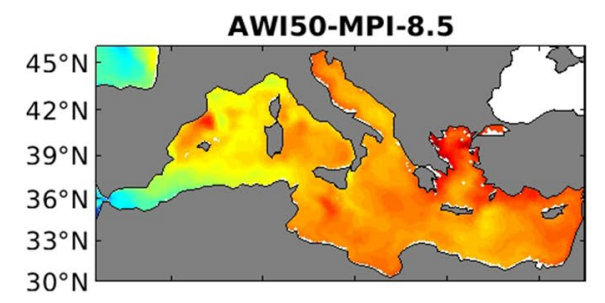

LMD-CNRM-8.5

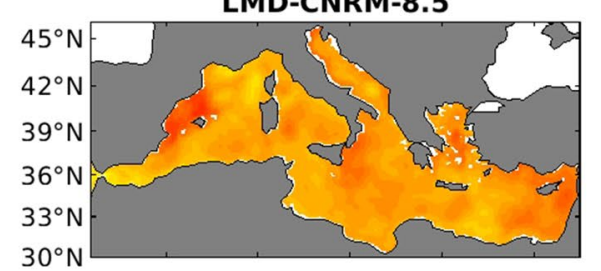

JRC-EC-4.5
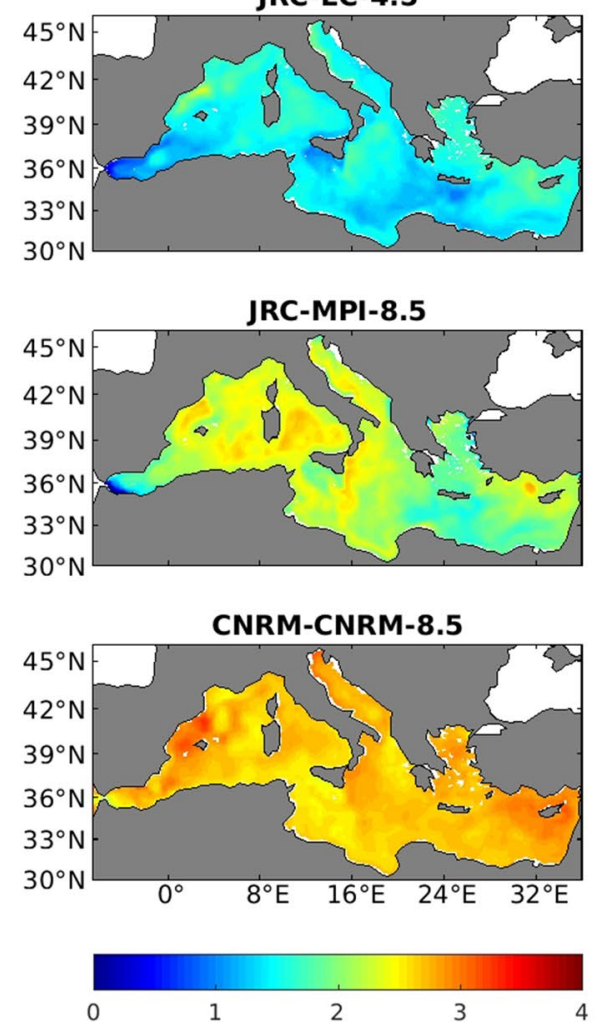

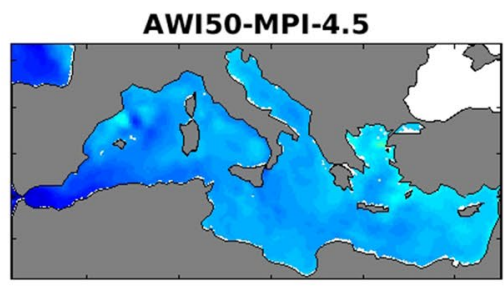

LMD-IPSL-8.5

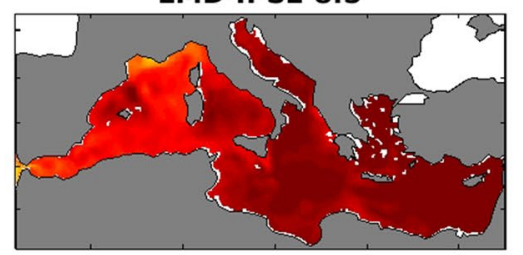

JRC-EC-8.5
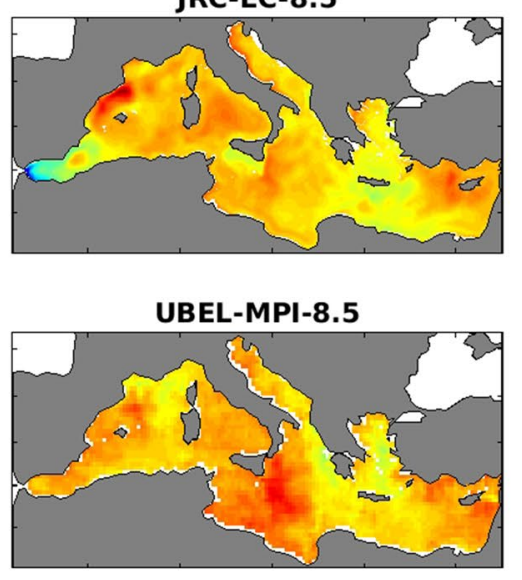

CNRM-CNRM-4.5

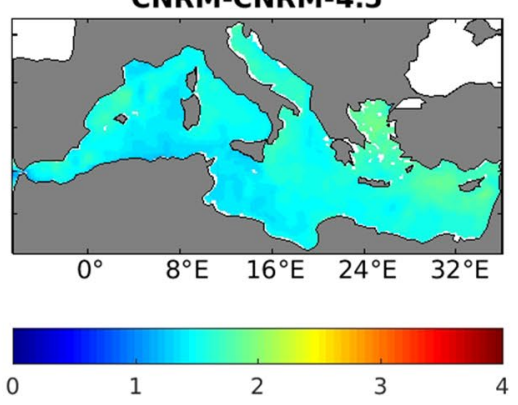

AWI25-MPI-8.5

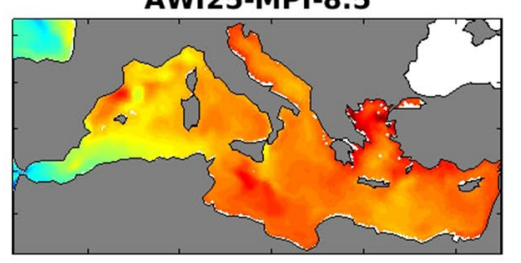

LMD-MPI-8.5

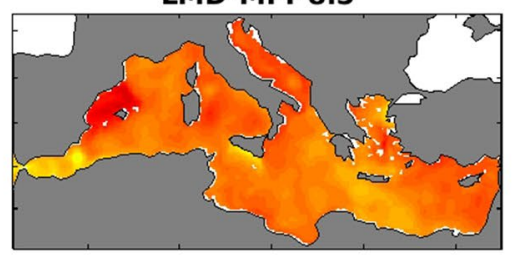

JRC-MPI-4.5

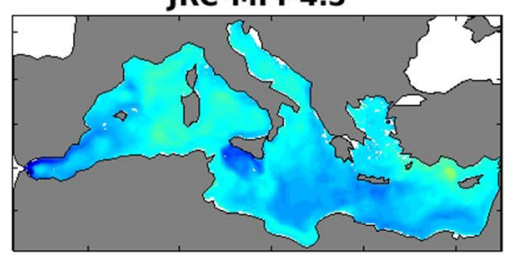

ENEA-CNRM-4.5

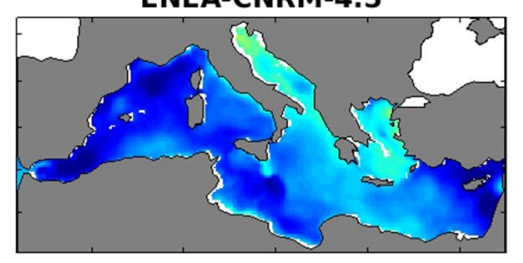

CNRM-CNRM-2.6
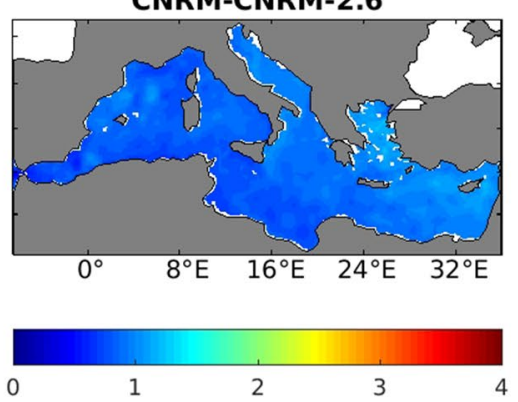

Fig. 2 SST anomaly fields $\left({ }^{\circ} \mathrm{C}\right)$ estimated as the difference between the average of the future (2075-2100) and present (1980-2005) conditions. The corresponding simulation is noted in the title of each panel 


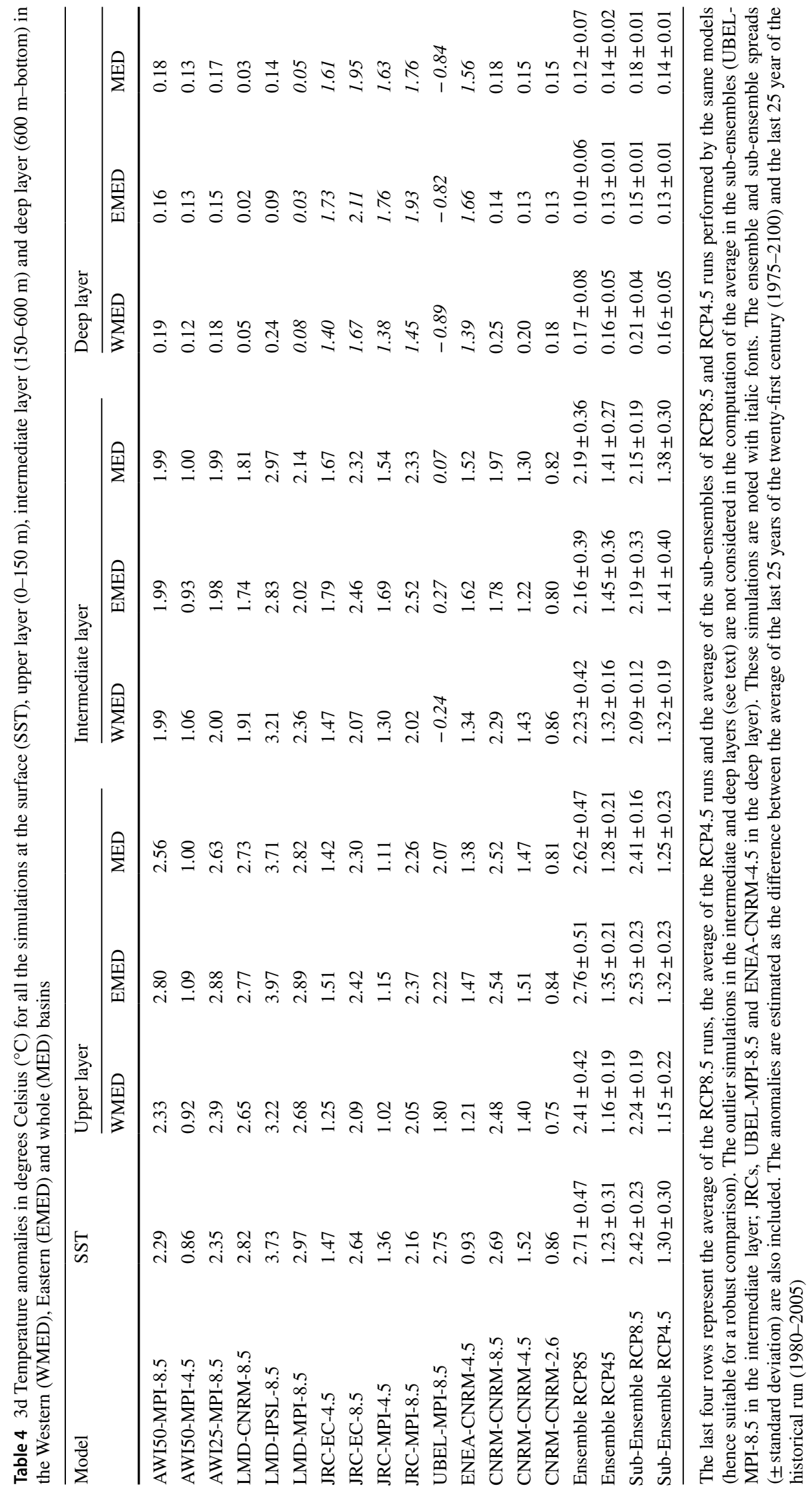


(Figure S15) allows an easy visualization of the simulations average differences (see SI for details).

The second important element of the simulations setup that determines the average SST evolution is the choice of global model in which the climate model is nested. For instance, if we focus our attention on the three LMDs simulations, which only differ in the global model they use (Table 1), clear differences can be observed (Fig. 2, Table 4). The spatial distribution of the warmer and colder areas is similar but the averaged increase of SST in the whole basin is around $3.73{ }^{\circ} \mathrm{C}$ in the simulation nested into IPSL-CM5AMR, a 25\% higher than for the one nested to CNRM-CM5 (Fig. S15; Table 4). This effect is also present between the two RCP 8.5 simulations of the JRC: the anomalies in the simulation nested into EC-Earth are $2.64{ }^{\circ} \mathrm{C}$, a 20\% higher than those in the simulation nested into MPI-ESMLR. Under the RCP 4.5 scenario the differences between the two JRC simulations are smaller $(\sim 10 \%)$, the one using ECEarth being slightly warmer (Fig. S15, Table 4). The choice of the regional model has also an impact on the averaged warming. Different simulations forced by the same global model MPI under the RCP8.5 shows a warming of $2.16^{\circ} \mathrm{C}$, $2.35^{\circ} \mathrm{C}$ and $2.97{ }^{\circ} \mathrm{C}$ (for JRC-MPI-8.5, AWI25-MPI-8.5 and LMD-MPI-8.5).

Concerning the spatial structures of the SST anomalies, in general, all simulations show similar features. First, all of them show a rather homogeneous warming across the basin. Overimposed, there is a longitudinal gradient with higher anomalies towards the Eastern basin. There is also coincidence in the location of the regions where the anomalies are especially high, such as the Levantine Basin (concretely in the area surrounding Cyprus), North of the Aegean and Adriatic Seas and the Balearic Sea. However, the specific location, extension and intensity of these warmer areas are not the same for all the simulations. Interestingly, if we check the spatial correlation of SST anomalies among models (see Fig. S16) we find that the simulations based on the same RCM are highly correlated among them. On the other hand, the correlation between runs from different models significantly varies, from very low or even negative values to values higher than 0.6. The choice of the GCM does not have such a noticeable impact in the spatial distribution of the SST. Finally, it is also worth pointing out the very small difference introduced by the increase of resolution in the atmospheric component of the AWIs simulations. AWI25MPI-8.5 and AWI50-MPI-8.5, with $25 \mathrm{~km}$ and $50 \mathrm{~km}$ atmospheric resolution respectively, show the same SST spatial patterns, with only a small increase in the anomalies in the former $\left(\sim 0.06{ }^{\circ} \mathrm{C}\right.$, Table 1 , Fig. 1$)$.

In order to make the comparison of the scenarios more meaningful, we have selected the sub-ensembles of simulations that are run under both RCP8.5 and RCP4.5 scenarios. The results of the averaged SST anomaly for both sub-ensembles are summarized in Fig. 3. The ensemble of RCP8.5 runs show an increase between 1.5 and $2{ }^{\circ} \mathrm{C}$, higher than the ensemble of RCP4.5 runs. These differences are quite homogeneous over the basin. They are slightly lower in the Adriatic and the Aegean Seas $\left(\sim 1.5^{\circ} \mathrm{C}\right)$, and slightly higher in the Northwestern Mediterranean, the Ionian Sea and the Levantine basin $\left(\sim 2{ }^{\circ} \mathrm{C}\right)$. The regional differences among models described before are reflected into the ensemble spread (standard deviation). For the RCP8.5 runs the higher discrepancies among models $\left(0.6-0.9^{\circ} \mathrm{C}\right)$ are found in the Strait of Gibraltar area, and wide areas in the Levantine basin, the Aegean and the Ionia Seas. In the RCP4.5 ensemble the spread is generally lower, with higher values $\left(\sim 0.6{ }^{\circ} \mathrm{C}\right)$ in the Alboran Sea and the Northwestern Mediterranean.

\subsection{D temperature}

The time series of anomalies of temperature for the surface, intermediate and deep layers are represented in Fig. 4 (for clarity only the RCP 8.5 simulations are included in the figure). Table 4 summarizes the temperature anomalies for all simulations distributed by layers and basins. The dashed lines and discolored bars in Fig. 4 indicate the simulations that showed anomalous drifts in the intermediate and deep layers in the historical runs. These runs have not been included in the computation of the ensemble anomalies of Table 4 (noted with italic fonts) (UBELMPI-8.5 in the intermediate layer; JRCs, UBEL-MPI-8.5 and ENEA-CNRM-4.5 in the deep layer). In the upper layer, all the simulations show an increase of temperature in both sub-basins but higher in the Eastern one in all cases. This increase (for the whole basin) among the RCP8.5 scenario runs ranges between $3.7^{\circ} \mathrm{C}$ for LMD-CNRM-8.5 simulation and $2.0^{\circ} \mathrm{C}$ for UBEL-MPI-8.5. For the RCP4.5 runs the maximum warming is $1.4^{\circ} \mathrm{C}$ for CNRM-CNRM- 4.5 simulation and the minimum $1{ }^{\circ} \mathrm{C}$ for AWI50-MPI-4.5. Under the RCP2.6 scenario only one simulation is available (CNRMCNRM-2.6) which shows an averaged warming of $0.84{ }^{\circ} \mathrm{C}$ at the end of the century (Table 4). The results are in good agreement with the results presented above for the SST. The simulations that showed higher SST anomalies are the ones projecting higher warming in the surface layer, with strong dependence on the scenario and the global models they use.

In the intermediate layer a substantial temperature increase is also projected by most simulations ranging from 1.1 to $2.9^{\circ} \mathrm{C}$. Larger/smaller changes are projected by those models which also project larger/smaller changes in the upper layer (Fig. 4). In this layer the warming of the Western and Eastern basins is very similar in most models and consequently in the ensemble mean. The outlier is UBELMPI-8.5, which shows a slightly warming in the Eastern basin $\left(0.2{ }^{\circ} \mathrm{C}\right)$ and even a slightly cooling in the WMED 

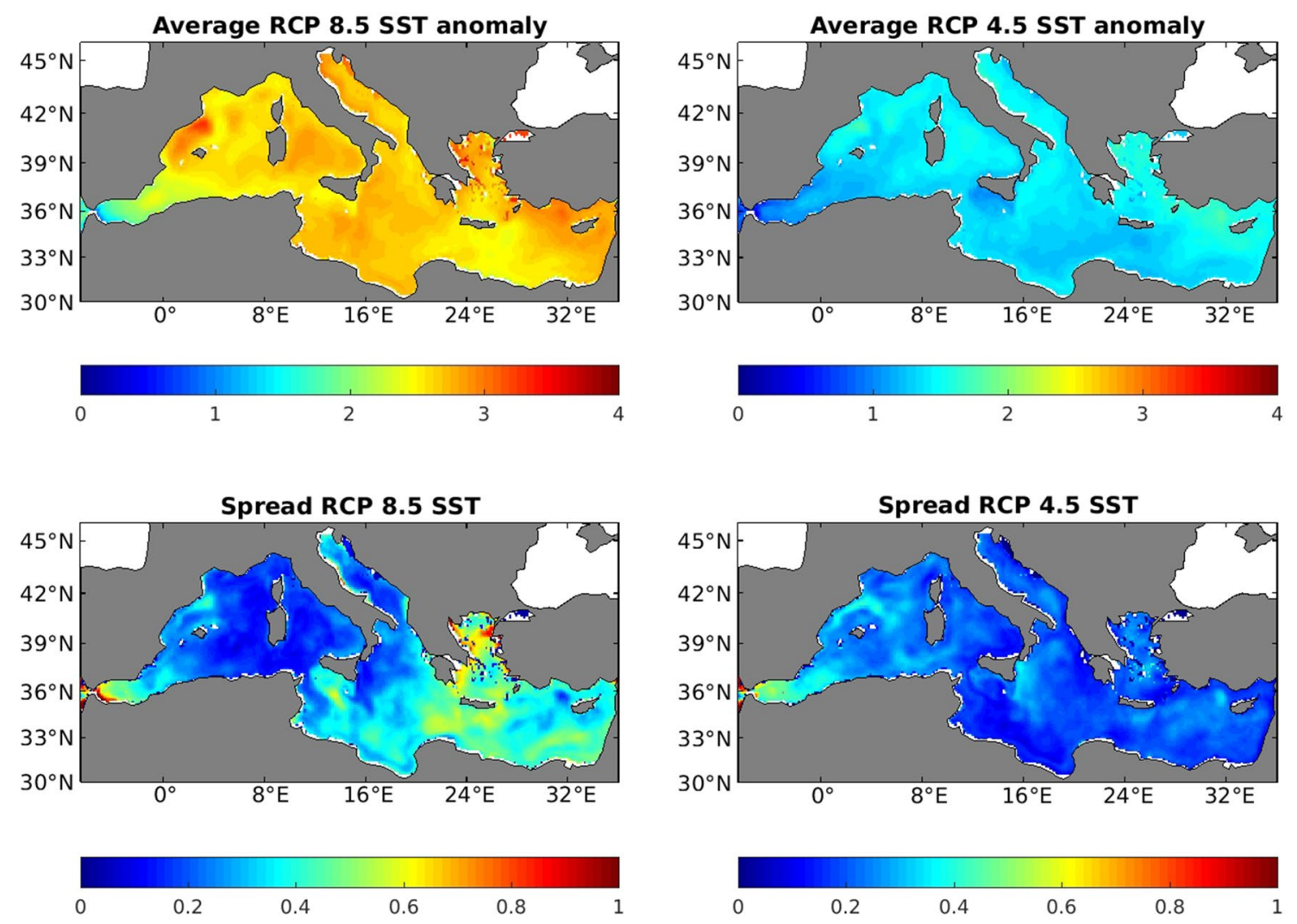

Fig. 3 Average SST anomalies $\left({ }^{\circ} \mathrm{C}\right.$ ) for the RCP 8.5 runs (top left) and RCP 4.5 runs (top right). The bottom left and right panels are the spread of the RCP 8.5 and RCP 4.5 sub-ensembles, respectively

$\left(-0.2^{\circ} \mathrm{C}\right)$, as a consequence of the above mentioned drift. For the entire basin, the ensemble average shows a warming in the intermediate layer of $2.16^{\circ} \mathrm{C}$ under the RCP8.5 scenario. When only the sub-ensemble run under both scenarios is considered the warming is $2.15^{\circ} \mathrm{C}$ for the RCP8.5 scenario and $1.38^{\circ} \mathrm{C}$ for the RCP4.5 scenario.

In the deep layer the runs with strong temperature drifts in the historical period introduce a very significant bias in the ensemble-mean statistics. UBEL-MPI-8.5 has strong negative anomalies, while JRCs and ENEA-CNRM-4.5 have very high positive anomalies (Table 4 ). The projected change in these simulations is one order of magnitude larger than for some of the runs of the rest of the ensemble. The drift is very clear in the time series representation of Fig. 4 (dashed lines for JRCs, and UBEL-MPI-8.5; note that the $\mathrm{y}$-axis scale in the panel has been widen to highlight the strong differences between drifting and non-drifting simulations). When excluding them from the ensemble average computation, the projected change of temperature for the whole basin in the deepest layer is $0.12{ }^{\circ} \mathrm{C}$ under the RCP8.5 scenario, and $0.14{ }^{\circ} \mathrm{C}$ under RCP4.5.

\subsection{Heat budget evolution}

In order to understand the mechanisms responsible of the warming described in the previous section the heat budget has been analyzed, separating the contributions of the surface heat flux and the heat exchange through the Strait of Gibraltar.

The temporal evolution of the basin heat content is approximated by the equations:

$\frac{d H C_{M e d}}{d t}=Q_{\text {Surf }}+Q_{\text {Gib }}$

$C p V \rho \frac{d T}{d t}=Q_{\text {Surf }}+C p \rho\left(G_{\text {in }} T_{\text {Gin }}-G_{\text {out }} T_{\text {Gout }}\right)$

The left hand side of Eq. 1 is the temporal derivative of the basin heat content (HC) that is equal to the sum of the heat flux at the sea surface $\left(Q_{\text {Surf }}\right)$ and the heat exchanged through Gibraltar $\left(Q_{G i b}\right)$. In Eq. 2, developing the term on the left hand side of Eq. 1, we have the water specific heat, $C_{p}$, the basin volume, $V$, the water density, $\rho$, and the time derivative of the basin temperature, $d T / d t$. On the second term of the right hand side we have simplified the Gibraltar 

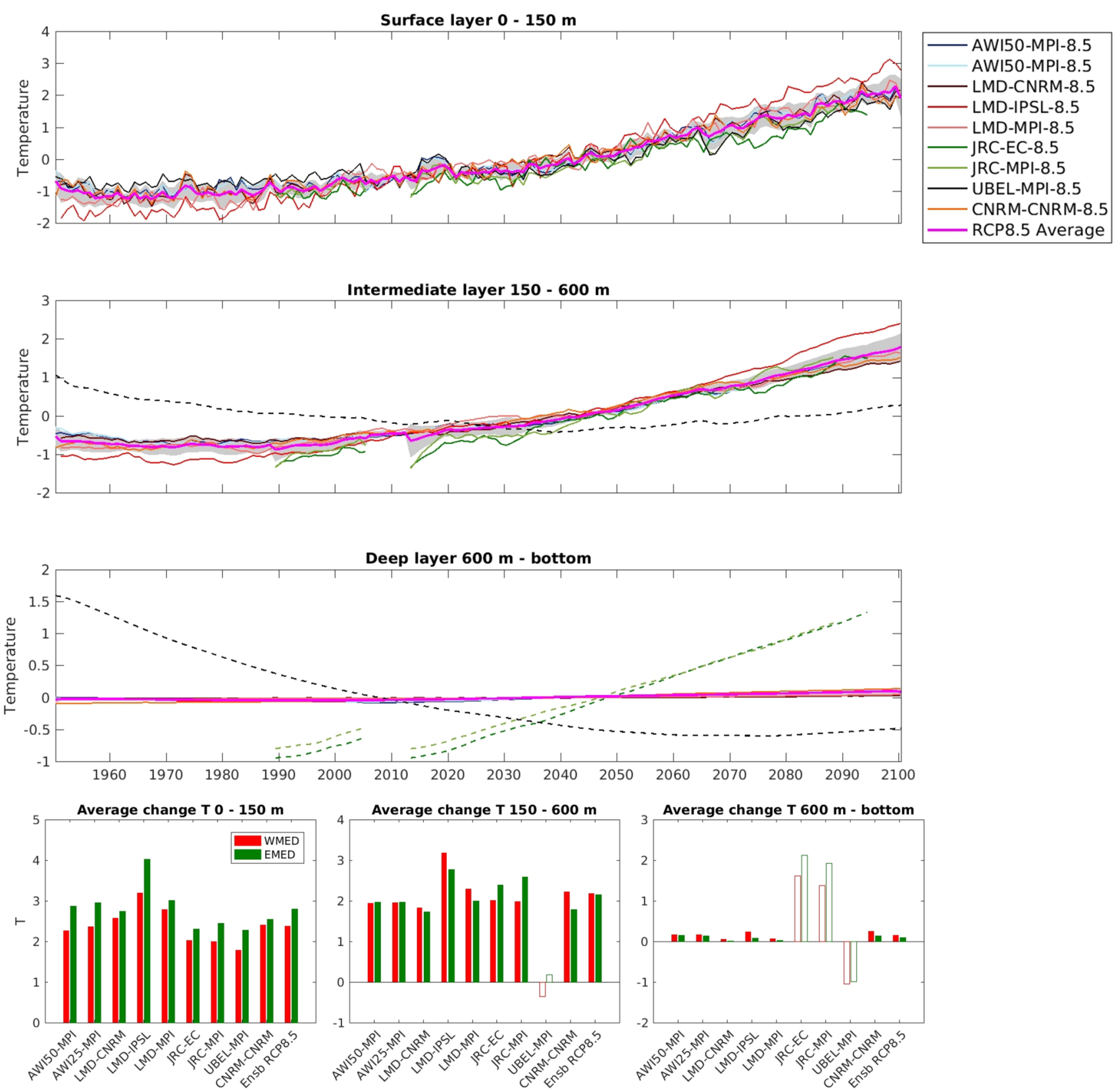

Fig. 4 Time series of the basin $3 \mathrm{~d}$ averaged temperature $\left({ }^{\circ} \mathrm{C}\right)$ at the upper (0-150 m, top panel), intermediate (150-600 m, middle panel) and deep (600 m-bottom, bottom panel) layers for the RCP 8.5 simulations. The magenta thick line is the ensemble mean and the shaded area represents the ensemble standard deviation. The bars in the bottom row represent the average temperature anomalies between the

exchange as a two layer exchange (Soto-Navarro et al. 2010), so $G_{\text {in(out })}$ and $T_{\text {in (out) }}$ are the volume transport of the inflow (outflow) and the inflow (outflow) temperature respectively. It is worth mentioning that the inflow is composed by Atlantic waters while the outflow is mainly composed by Mediterranean intermediate waters. future (2075-2100) and the present (1980-2005) at each layer for the Western (red) and Eastern (green) basins for each model. Note the different vertical axis. The dashed lines and discolored bars indicate the simulations with anomalous drifts (see text). These simulations are not considered in the computation of the ensemble average

The averaged values for the end of the historical runs (1980-2005) and for the end of the twenty-first century projections (2075-2100) of the heat content change (HCC), the surface heat flux $\left(\mathrm{Q}_{\text {Surf }}\right)$ and the heat flux through the Strait of Gibraltar (QG) are summarized in Table 5. It is important to point out that the closure of the heat budget is not always achieved due to the use of monthly data in the computation. 
On-line computation at higher frequency would provide more precise results but unfortunately were not available for most simulations.

In the present climate the ensemble average shows a warming (i.e. a positive $\mathrm{HCC}$ of 2.08 and $0.43 \mathrm{~W} / \mathrm{m}^{2}$ for RCP8.5 and RCP4.5 ensembles, respectively) due to the excess of heat entering through Gibraltar which is not compensated by the heat loss through the sea surface. It has to be noted that the contribution of ENEA-CNRM-4.5 and JRCs runs, which shows large warming (i.e. see previous results), drives the ensemble averages. During the twentyfirst century, the ensemble also shows an increase in the $\mathrm{HC}$, again because the input through Gibraltar exceeds the heat losses through the sea surface. In particular, the heat losses through the surface reduces almost $50 \%$, and even though the input through the Strait of Gibraltar decreases due to the warming of the intermediate waters (i.e. more heat loss by the outflow to the Atlantic), the result is an intensification of the basin heat content and the subsequent rise of the water temperature (see Table 5).
A detailed analysis of the contribution of the different terms in Table 5 is puzzling. If we focus on the simulations showing a more stable behavior during the historical period (CNRMs, AWIs and LMDs), we see that there is an acceleration of the warming (i.e. HCC during 2075-2100 is larger than during 1985-2005). This is caused by the decrease in the surface heat loss, while the contribution of Gibraltar fluxes is less clear. In CNRMs runs an increase in the heat inflow is found due to the warming of inflowing waters, while in AWIs runs a decrease in the net heat inflow is found because of the temperature increase in the outflowing waters. If we focus on other simulations the behavior is more confusing. For instance, JRCs and ENEA-CNRM-4.5 simulations show a deceleration of the warming (i.e. HCC in the twenty-first century smaller than during the twenty-first century), but this is probably caused by the large unrealistic warming those simulations show in the historical period.

Summarizing the heat budget analysis, most models show a decrease in the heat loss through the sea surface and

Table 5 Summary of the basin heat budget for the different simulations. HCC is the heat content change of the basin, estimated as the left-hand side term Eq. 2 (see text)

\begin{tabular}{|c|c|c|c|c|c|c|c|c|c|}
\hline \multirow[t]{2}{*}{ Model } & \multicolumn{3}{|l|}{ 1980-2005 } & \multicolumn{3}{|l|}{$2075-2100$} & \multicolumn{3}{|l|}{ CHANGE } \\
\hline & $\mathrm{HCC}$ & $\mathrm{Q}_{\text {Surf }}$ & QG & $\mathrm{HCC}$ & $\mathrm{Q}_{\text {Surf }}$ & QG & $\mathrm{HCC}$ & $\mathrm{Q}_{\text {Surf }}$ & QG \\
\hline AWI50-MPI-8.5 & -0.26 & -3.07 & 3.46 & 2.46 & 3.34 & 0.60 & 2.72 & 6.41 & -2.86 \\
\hline AWI50-MPI-4.5 & -0.29 & -3.07 & 3.46 & 0.71 & 0.60 & 1.54 & 1.00 & 3.67 & -1.91 \\
\hline AWI25-MPI-8.5 & 0.04 & -2.60 & 3.47 & 2.36 & 3.45 & 0.46 & 2.32 & 6.04 & -3.01 \\
\hline LMD-CNRM-8.5 & 0.61 & N/A & N/A & 2.46 & N/A & N/A & 1.85 & N/A & N/A \\
\hline LMD-IPSL-8.5 & 2.02 & N/A & N/A & 3.31 & N/A & N/A & 1.29 & N/A & N/A \\
\hline LMD-MPI-8.5 & 1.67 & N/A & N/A & 2.23 & N/A & N/A & 0.56 & N/A & N/A \\
\hline JRC-EC-4.5 & 6.25 & -6.22 & 12.47 & 4.13 & -8.29 & 12.43 & -1.16 & -1.05 & -0.11 \\
\hline JRC-EC-8.5 & 6.25 & -6.22 & 12.47 & 5.41 & -7.63 & 13.04 & -0.14 & -0.47 & 0.33 \\
\hline JRC-MPI-4.5 & 6.96 & -5.16 & 12.41 & 4.09 & -8.73 & 12.92 & -1.04 & -1.23 & 0.28 \\
\hline JRC-MPI-8.5 & 6.96 & -5.16 & 12.41 & 5.43 & -8.00 & 13.42 & -0.46 & -1.06 & 0.60 \\
\hline UBEL-MPI-8.5 & -3.73 & -4.53 & 4.17 & 2.10 & 0.61 & 5.65 & 5.84 & 5.14 & 1.47 \\
\hline ENEA-CNRM-4.5 & 3.82 & N/A & N/A & 3.12 & N/A & N/A & -0.70 & N/A & N/A \\
\hline CNRM-CNRM-8.5 & 1.13 & -3.24 & 5.40 & 2.69 & -1.15 & 5.50 & 1.56 & 2.09 & 0.10 \\
\hline CNRM-CNRM-4.5 & 1.13 & -3.24 & 5.40 & 1.53 & -2.24 & 5.58 & 0.41 & 1.00 & 0.18 \\
\hline CNRM-CNRM-2.6 & 1.14 & -3.24 & 5.40 & -0.20 & -4.07 & 5.57 & -1.34 & -0.83 & 0.17 \\
\hline Ensemble RCP8,5 & $2.08 \pm 2.37$ & $-4.60 \pm 2.25$ & $7.57 \pm 4.81$ & $3.15 \pm 1.48$ & $-2.22 \pm 5.61$ & $6.62 \pm 6.38$ & $1.07 \pm 1.16$ & $2.39 \pm 3.59$ & $-0.95 \pm 1.81$ \\
\hline Ensemble RCP4,5 & $0.42 \pm 1.00$ & $-3.16 \pm 0.12$ & $4.43 \pm 1.37$ & $1.12 \pm 0.58$ & $-0.82 \pm 2.01$ & $3.56 \pm 2.85$ & $0.71 \pm 0.42$ & $2.34 \pm 1.89$ & $-0.87 \pm 1.48$ \\
\hline $\begin{array}{l}\text { Sub-Ensemble } \\
\text { RCP8,5 }\end{array}$ & $0.30 \pm 0.73$ & $-2.97 \pm 0.33$ & $4.11 \pm 1.12$ & $2.50 \pm 0.17$ & $1.88 \pm 2.62$ & $2.19 \pm 2.87$ & $2.20 \pm 0.59$ & $4.85 \pm 2.39$ & $-1.92 \pm 1.75$ \\
\hline $\begin{array}{l}\text { Sub-Ensemble } \\
\text { RCP4,5 }\end{array}$ & $0.42 \pm 1.00$ & $-3.16 \pm 0.12$ & $4.43 \pm 1.37$ & $1.12 \pm 0.58$ & $-0.82 \pm 2.01$ & $3.56 \pm 2.85$ & $0.71 \pm 0.42$ & $2.34 \pm 1.89$ & $-0.87 \pm 1.48$ \\
\hline
\end{tabular}

$\mathrm{Q}_{\text {Surf }}$ is the surface heat flux. QG is the heat exchange through the Strait of Gibraltar, estimated as the second term of the right-hand side of Eq. 2. The changes on each term have been computed as the difference between the average of the last 25 years of historic runs (1980-2005) and the average of the last 25 years of the twenty-first century projections (2075-2100). The last four rows represent the average of the RCP8.5 runs, the average of the RCP4.5 runs and the average of the sub-ensembles of RCP8.5 and RCP4.5 runs performed by the same model (hence suitable for a robust comparison). The ensemble and sub-ensemble spreads ( \pm standard deviation) are also included. N/A means that the data is not available for that simulation. Units are $\mathrm{W} / \mathrm{m}^{2}$ 
only the JRCs simulations show an increase. In this case it is worth recalling that JRCs is the only simulation run in forced mode and using bulk formulae to estimate the heat fluxes. For the contribution of the fluxes through the Strait of Gibraltar most simulations show an increase in the net heat flux due to the warming of the inflowing waters. Only the AWIs simulations show a decrease in the net heat flux due to the warming of the outflowing waters (i.e. more heat transfer to western Mediterranean intermediate waters).

\section{Salinity evolution in the twenty-first century}

\subsection{Sea surface salinity}

The anomalies of the Sea Surface Salinity (SSS) computed as the difference between the average of the end of the twenty-first century (2075-2100) and the average of the end of the historical run (1980-2005) are represented in Fig. 5 and summarized in Table 6. At first sight the contrast with the SST anomalies of Fig. 2 is evident. For the SSS the gradient between the Western and Eastern basins is very pronounced in all simulations. In the Western Mediterranean we find very low or even negative anomalies for AWIs, LMDs and CNRMs simulations while for the Eastern basin the salinity increases in all the runs. In the whole basin the SSS changes between -1 and +2 psu, while by sub-basins is -1 and +1 psu in the WMED and between 0 and +2 psu in the EMED. This behavior suggests that the values imposed at the lateral boundary condition in the Atlantic may be determining the evolution of the western basin. In other words, models forced by GCMs in which NE Atlantic SSS decrease in the future projections, show a moderate increase (or even a reduction) in the western basin SSS compared to the evolution of the Eastern basin SSS. The higher anomalies are shown by UBEL-MPI- 8.5 and JRCs simulations, with average values between 0.40 and 0.87 psu for the basin, and the lower by AWIs simulations, all three showing negative mean values between -0.25 and -0.17 psu (Table 6 ).

Another significant difference with the SST is that the choice of the emission scenario plays a secondary role in the SSS evolution. Some differences are found between simulations run under RCP 8.5 and RCP 4.5 scenarios but the results don't show a clear response. The differences between scenarios are smaller than the differences of both scenarios with respect to present conditions. Conversely, the choice of the modeling system seems to play the capital role in explaining the discrepancies among simulations. The spatial distribution and magnitude of the anomalies in the subsets of simulations that share the same regional climate model (AWIs, LMDs, JRCs and CNRMs) are very similar among them and different to the rest (Figs. 4, S15). Among the RCM characteristics, the simulation of river discharge could be also influencing the evolution of the SSS. However, the largest differences are found in the Western Mediterranean in spite of the fact that large rivers exist in the eastern basin, so we would expect large discrepancies there if the future river runoff played a relevant role. The choice of global model also has an impact. For instance, the three LMDs simulations show discrepancies in the intensity of the anomalies depending on the global model used (Fig. 5, S15).

In Fig. 6 the ensemble mean of SSS anomalies for the RCP 8.5 and the RCP 4.5 simulations together with the ensemble spread are presented. We see that the spatial distribution and the magnitudes of the anomalies are very close for both scenarios, with spatial differences larger than differences between scenarios. The areas with higher values are located in the Eastern basin, especially intense in the northern Aegean and the Adriatic seas, with projected SSS anomalies reaching $1.5 \mathrm{psu}$. The strong anomalies in the Aegean, present in many simulations (Fig. 4), are likely the effect of a decrease in the freshwater input from the black Sea. This reduction in the second half of the 21 st has been previously reported (Dubois et al. 2012) and linked to a reduction in the precipitation over the catchment basin that feeds the Black Sea (Mariotti et al. 2008). The different parameterization of the Black Sea in the models conditions freshwater input variability and hence the changes in the salinity of the Aegean Sea. In consequence, the response is different among simulations.

The smaller anomalies are distributed along the western basin, with a clear gradient towards the east and with the lowest values in the Alboran Sea and along Spanish continental slope. The spread among simulations is generally higher for the RCP 8.5 scenario with an average value of $0.31 \mathrm{psu}(0.20 \mathrm{psu}$ for the RCP4.5). The spread in the RCP8.5 sub-ensemble is larger in the areas with the stronger anomalies: the Aegean and the Alboran seas. The former is linked to the discrepancies among models in the contribution of the Black Sea (see Fig. 5), while the latter is linked to the differences in the properties of Atlantic waters inflowing into the Mediterranean. Conversely, the spread is much smaller in the Adriatic Sea, with values lower than 0.2 psu. In the RCP 4.5 sub-ensemble the spread is larger in the Levantine basin, south of Sicily and the Alboran Sea. On the other hand, despite the differences pointed out, in the case of the SSS the discrepancies in the spatial distribution of the simulations is much smaller than for the SST: most pairs of simulations show correlations in the spatial pattern close to 1 (see Figure S15). 


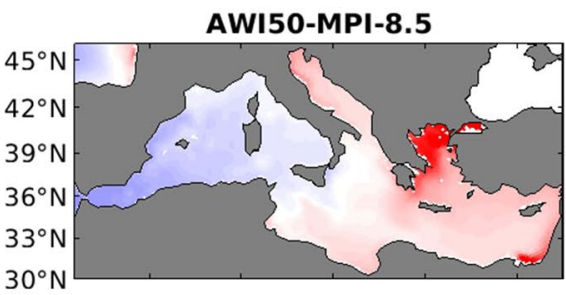

LMD-CNRM-8.5

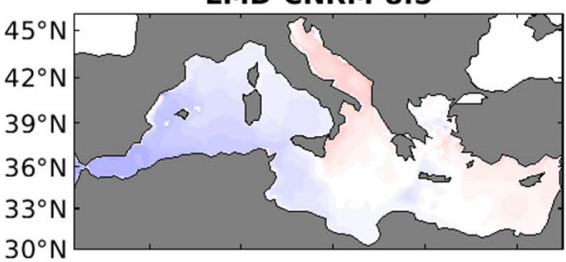

JRC-EC-4.5

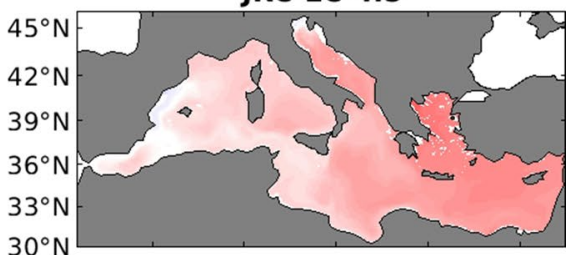

JRC-MPI-8.5

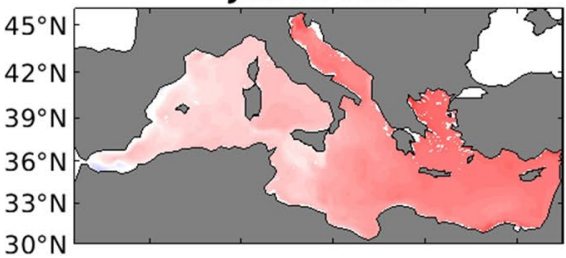

CNRM-CNRM-8.5

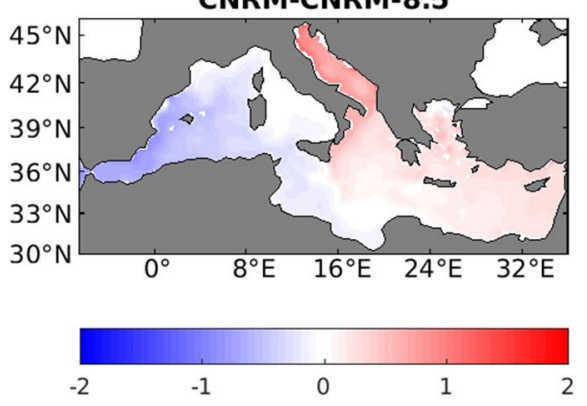

AWI50-MPI-4.5

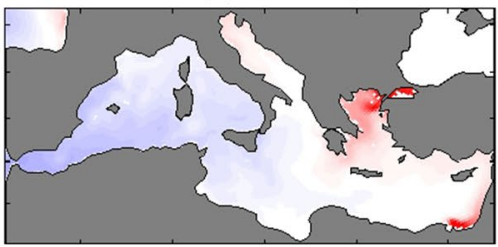

LMD-IPSL-8.5

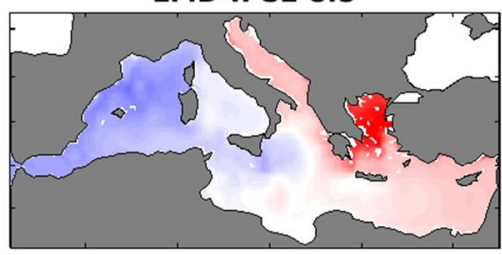

JRC-EC-8.5

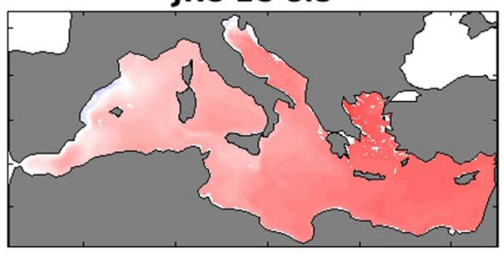

UBEL-MPI-8.5

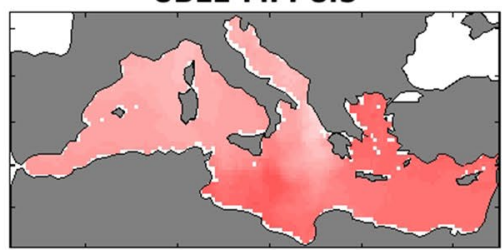

CNRM-CNRM-4.5
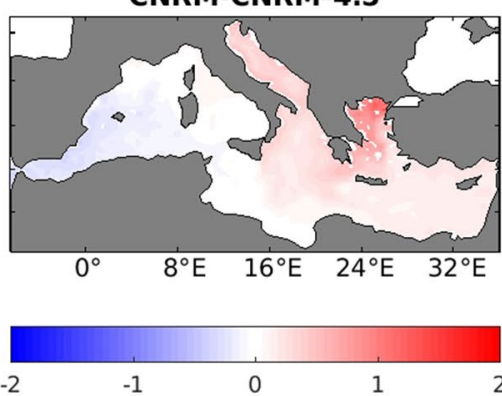

AWI25-MPI-8.5

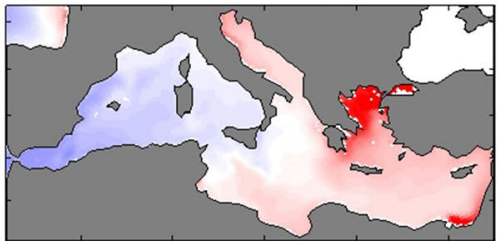

LMD-MPI-8.5

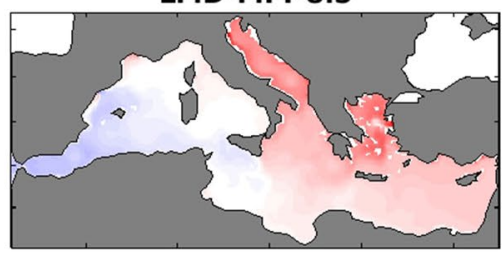

JRC-MPI-4.5

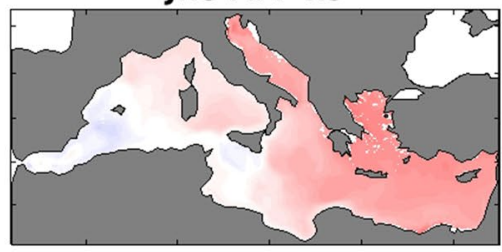

ENEA-CNRM-4.5

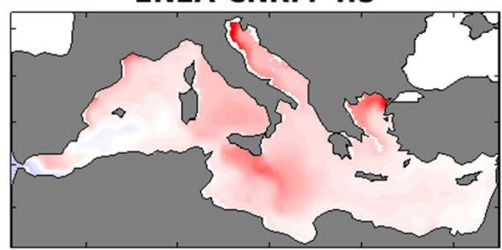

CNRM-CNRM-2.6
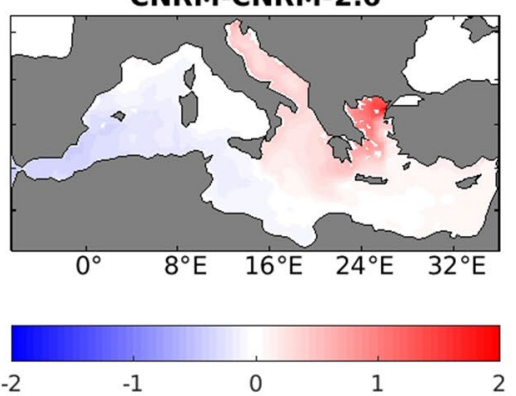

Fig. 5 Same as Fig. 2 but for the sea surface salinity (psu)

\subsection{D salinity}

Figure 7 displays the time series of anomalies of salinity for the upper, intermediate and deep layers in the RCP 8.5 runs. The histograms represent the mean change between the end of the twenty-first century (2075-2100) and the historical run (1980-2005). Again, the simulations that showed unrealistic drifts in the historical run (JRCs and UBEL-MPI-8.5) have been excluded of the ensemble average computation (noted with dashed lines and discolored bars in Fig. 6, and italic fonts in Table 6). In the upper layer most of the simulations show an increase of salinity for the whole basin ranging between 0.05 and $0.67 \mathrm{psu}$, for LMD-IPSL-8.5 and UBELMPI-8.5, respectively (see Table 6). Only LMD-CNRM-8.5 has a mean negative value $(-0.07 \mathrm{psu})$. The longitudinal gradient observed for the SSS is also very clear in this layer with higher salinization in the Eastern basin. In fact, all runs show a salinity increase in the Eastern Mediterranean, while some simulations (AWIs, LMDs and CNRMs) even project negative anomalies in the WMED (Table 6). Under the 

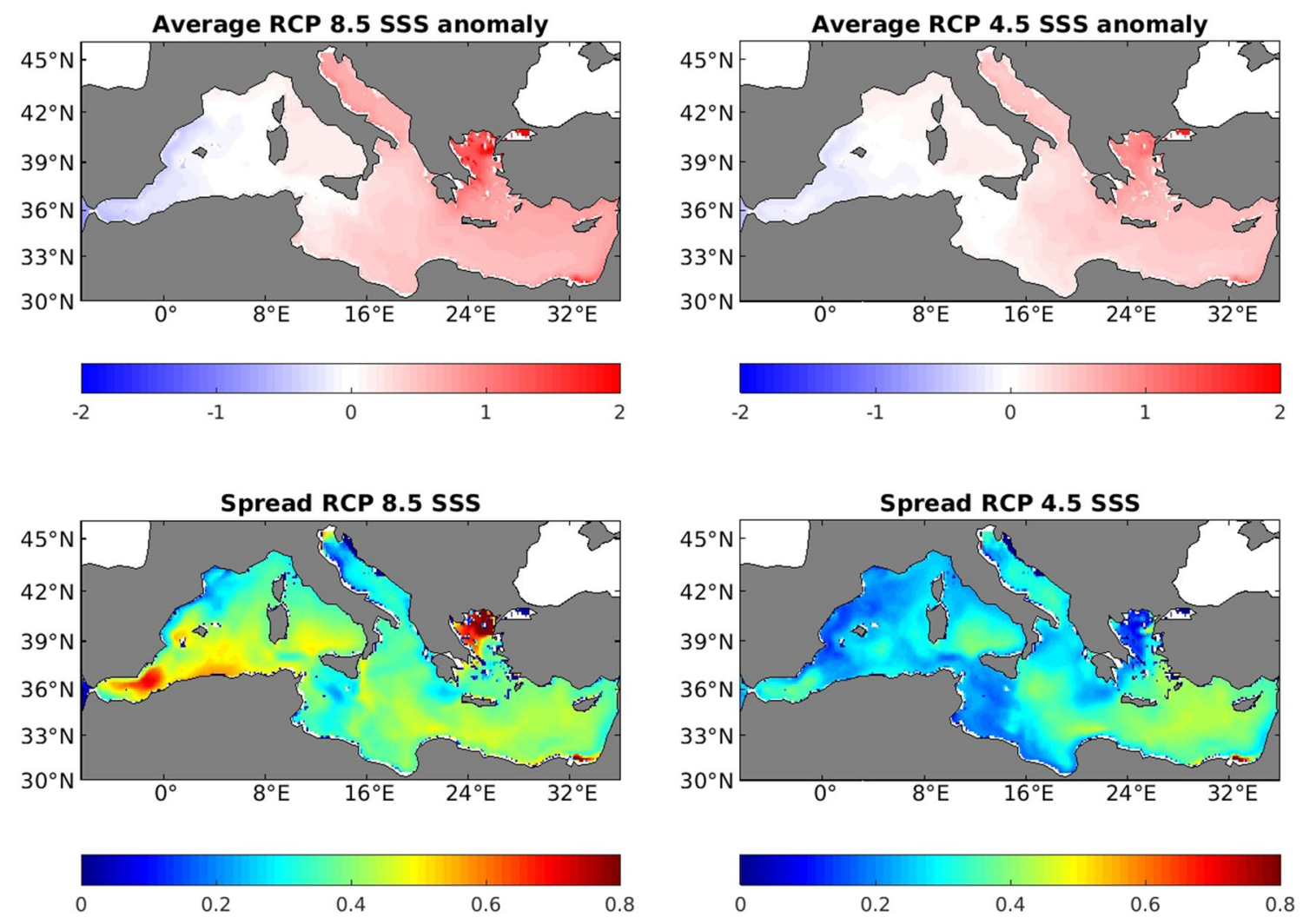

Fig. 6 Same as Fig. 3 but for the SSS (psu)

RCP 4.5 scenario, the anomalies for the whole basin range between -0.09 psu (AWI50-MPI-4.5) and 0.92 psu (ENEACNRM-4.5), and the larger anomalies in the eastern basin with respect to the Western Mediterranean are also observed (Table 6). As previously mentioned, this strong salinity gradient is likely the result of the open boundary condition of the models at the Strait of Gibraltar. The average for the sub-ensembles using the same RCMs shows that in this layer the choice of RCP scenario gains relevance in comparison to the surface layer. The mean anomalies of the RCP 8.5 runs are higher than for the RCP 4.5 runs, especially in the EMED (Table 6).

In the intermediate layer the differences between the Western and Eastern basins fade away and the anomalies are positive for all the RCP 8.5 simulations in both basins (except for LMD-CNRM-8.5), ranging between 0.75 and 0.22 psu (UBEL-MPI-8.5 and CNRM-CNRM-8.5). The waters of the eastern basin show a distribution that is way more homogeneous. The average increase of the RCP 8.5 sub-ensemble is 0.32 psu (0.32 WMED and 0.32 EMED). For the RCP 4.5 runs the average increase is less than half, 0.15 psu for the whole basin (0.15 WMED and 0.15 EMED). Here again we see that the choice of RCP scenario plays a more significant role in the salinity evolution of the deeper layer than in the surface layer.

In the deeper layer the results are analogous to those of temperature. In general most simulations show an increase of salinity. Only LMD-CNRM-8.5 and LMD-MPI-8.5 show slightly negative anomalies. However, it is worth noting the large differences found between the projections of AWIs, LMDs and CNRMs simulations, with anomalies ranging between -0.05 and $0.05 \mathrm{psu}$, and JRCs, ENEACNRM-4.5 and UBEL-MPI-8.5, with values between 0.6 and $0.8 \mathrm{psu}$ (as for temperature, note that the y-axis scale in the panel has been widen to highlight the strong differences between drifting and non-drifting simulations).

The likely cause of this strong disagreement in JRC and ENEA is again the short (or lack of) spin up, which was not long enough to stabilize the deeper layer. These abnormally high trends were already present in the historical runs of JRCs (Fig. S14; Table 3). For UBEL-MPI-8.5 and ENEA-CNRM-4.5 the strong trends are observed only in the projection, so it may be linked to an enhanced salt flux to the deeper layers, that in UBEL-MPI-8.5 maybe caused by its coarse resolution. The mean increase for the RCP 8.5 sub-ensemble in the whole basin is $0.04 \mathrm{psu}$, 0.04 psu for the WMED and 0.03 psu for the EMED. For the RCP 4.5 runs the anomaly for the whole basin is 0.02 psu, 0.03 psu for the Western basin and 0.02 psu for the 

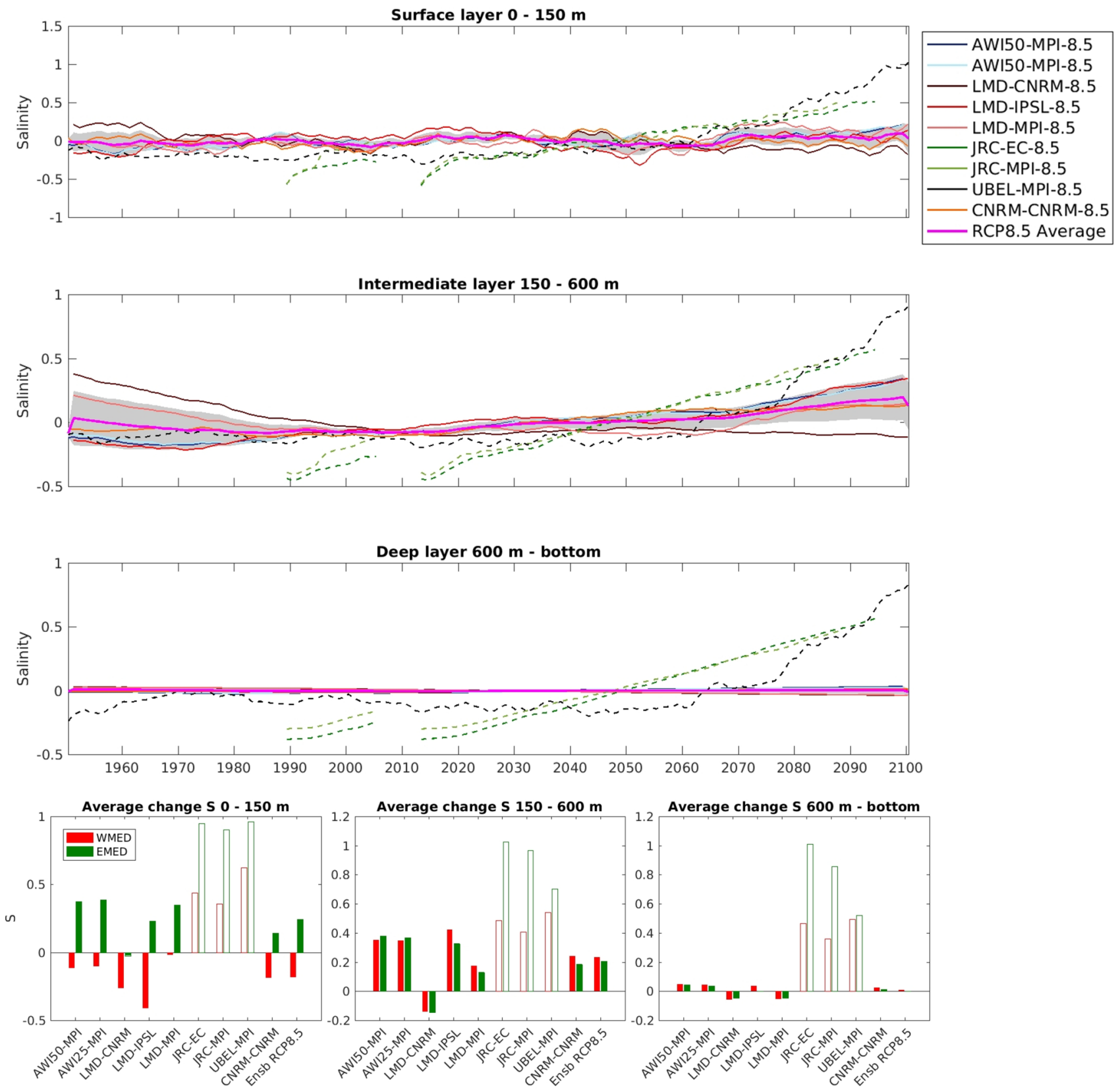

Fig. 7 Same as Fig. 4 but for salinity (psu)

Eastern basin (notice that JRCs simulation are excluded of the ensemble average computation).

\subsection{Salt budget}

The only mechanism through which the salt content of the Mediterranean basin can be modified is the exchange through the Strait of Gibraltar. Therefore, we can express the salt balance of the basin as:
$\Delta S=G_{\text {in }} S_{\text {Gin }}+G_{\text {out }} S_{\text {Gout }}$

where $\Delta S$ is the change in salt content, $G_{\text {in }}\left(G_{\text {out }}\right)$ is the inflow (outflow) volume transport and $S_{\text {in }}\left(S_{\text {out }}\right)$ the salinity of the inflow (outflow). The evolution of the salt content can then be described as: 


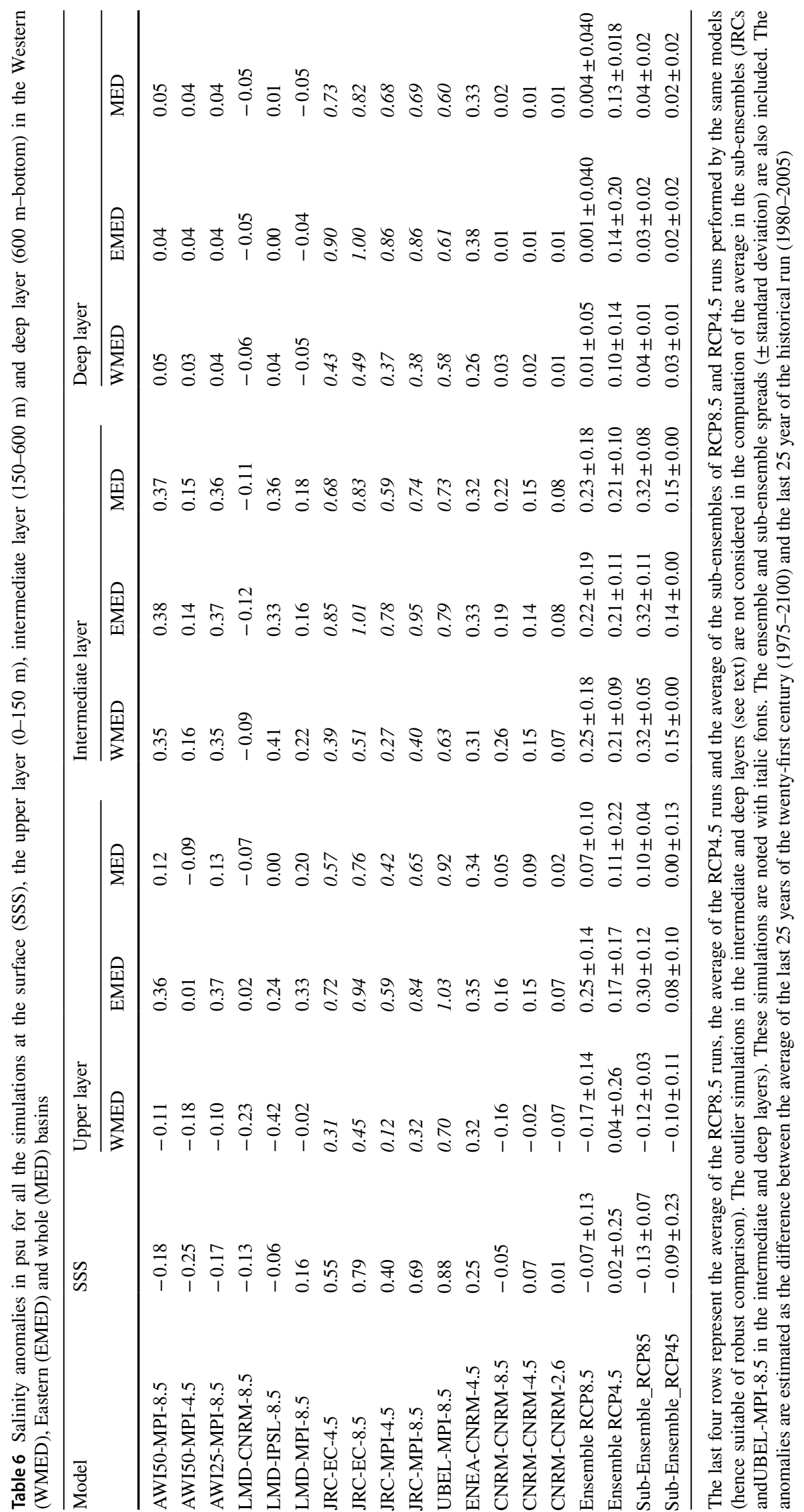




$$
\begin{aligned}
\Delta S_{\text {future }}= & \Delta S_{\text {present }}+\Delta G_{\text {in }} S_{\text {Gin }}+G_{\text {in }} \Delta S_{\text {Gin }} \\
& +\Delta G_{\text {out }} S_{\text {Gout }}+G_{\text {out }} \Delta S_{\text {Gout }}+O\left(\Delta^{2}\right) \\
\Delta S_{\text {future }}= & \Delta S_{\text {present }}+\left[\Delta G_{\text {in }} S_{\text {Gin }}+\Delta G_{\text {out }} S_{\text {Gout }}\right] \\
& +\left[G_{\text {in }} \Delta S_{\text {Gin }}+G_{\text {out }} \Delta S_{\text {Gout }}\right]+O\left(\Delta^{2}\right)
\end{aligned}
$$

where $\Delta G$ and $\Delta S$ are the changes between the future and present and the cross - terms of the development $\left(\Delta G_{\text {in(out })}\right.$ - $\left.\Delta S_{\text {in(out })}\right)$ have been neglected because they are very small in comparison with the rest. Hence, the change of salt in the future will be the combination of the imbalances in the present climate $\left(\Delta S_{\text {present }}\right)$, the contribution of the changes in water flow $\left(\Delta G_{\text {in(out })}\right)$, and the contribution of changes in salinity in the inflow/outflow $\left(\Delta S_{\text {in(out })}\right)$. In turn, the changes in the net water fluxes at Gibraltar are driven by changes in the surface freshwater budget $\Delta(E+P+R) \approx \Delta G_{\text {in }}+\Delta G_{\text {out }}$, where $\mathrm{E}$ stands for evaporation, $\mathrm{P}$ precipitation and $\mathrm{R}$ river runoff.
We can now check what is projected by the models for each term to assess which is expected to have larger influence on the Mediterranean salt content. Unfortunately, we do not have the necessary data to compute all the terms from all the simulations (what was available is summarized in Table 7). The salinity of the inflow decreases for most simulations, with an average reduction of 0.46 psu for the ensemble ( 0.60 for RCP 8.5 runs and 0.31 psu for RCP 4.5 runs). This means that the Atlantic waters entering through the Strait are fresher, a direct effect of the results of the global models in which the simulations are nested into, as commented in Sect. 4.1. Only UBEL-MPI-8.5 shows an important increase $(0.68 \mathrm{psu})$, while in JRCs there are no significant changes in the Atlantic waters salinity. On the other hand, the outflow waters become saltier in all simulations except LMD-CNRM-8.5. The average for the ensemble is $0.15 \mathrm{psu}, 0.20$ for the RCP 8.5 runs and 0.10 for the RCP 4.5 runs. This increase of the Mediterranean outflow waters

\begin{tabular}{|c|c|c|c|c|c|}
\hline Model & $\Delta \mathrm{S}_{\mathrm{in}}(\mathrm{psu})$ & $\Delta \mathrm{S}_{\text {out }}(\mathrm{psu})$ & $\Delta \mathrm{G}_{\mathrm{in}}(\mathrm{Sv})$ & $\Delta \mathrm{G}_{\text {out }}(\mathrm{Sv})$ & $\Delta(\mathrm{E}-\mathrm{P}-\mathrm{R})(\mathrm{mm} / \mathrm{d})(\mathrm{Sv})$ \\
\hline AWI50-MPI-8.5 & -1.10 & 0.30 & 0.01 & -0.05 & $0.52(0.015)$ \\
\hline AWI50-MPI-4.5 & -0.89 & 0.19 & -0.03 & 0.002 & $0.31(0.009)$ \\
\hline AWI25-MPI-8.5 & -1.14 & 0.35 & -0.05 & 0.01 & $0.55(0.016)$ \\
\hline LMD-CNRM-8.5 & -0.79 & -0.31 & N/A & N/A & N/A \\
\hline LMD-IPSL-8.5 & -1.10 & 0.62 & N/A & N/A & N/A \\
\hline LMD-MPI-8.5 & -0.52 & 0.02 & N/A & N/A & N/A \\
\hline JRC-EC-4.5 & 0.004 & 0.02 & -0.04 & 0.02 & $0.14(0.004)$ \\
\hline JRC-EC-8.5 & 0.001 & 0.01 & -0.01 & 0.05 & $0.35(0.010)$ \\
\hline JRC-MPI-4.5 & 0.003 & 0.02 & -0.02 & 0.003 & $0.28(0.008)$ \\
\hline JRC-MPI-8.5 & 0.004 & 0.01 & -0.001 & 0.06 & $0.52(0.015)$ \\
\hline UBEL-MPI-8.5 & 0.68 & 0.04 & N/A & N/A & $0.69(0.020)$ \\
\hline ENEA-CNRM-4.5 & -0.51 & 0.38 & N/A & N/A & N/A \\
\hline CNRM-CNRM-8.5 & -0.78 & 0.34 & 0.03 & -0.004 & $0.83(0.024)$ \\
\hline CNRM-CNRM-4.5 & -0.36 & 0.17 & 0.02 & -0.003 & $0.52(0.015)$ \\
\hline CNRM-CNRM-2.6 & -0.41 & 0.08 & 0.03 & -0.02 & $0.41(0.012)$ \\
\hline Ensemble RCP8.5 & $-0.48 \pm 0.50$ & $0.14 \pm 0.22$ & $-0.004 \pm 0.30$ & $0.01 \pm 0.04$ & $0.35 \pm 0.48(0.010 \pm 0.014)$ \\
\hline Ensemble RCP4.5 & $-0.29 \pm 0.27$ & $0.13 \pm 0.15$ & $-0.02 \pm 0.03$ & $0.005 \pm 0.010$ & $0.25 \pm 0.15(0.007 \pm 0.005)$ \\
\hline Sub-Ensemble RCP8.5 & $-0.60 \pm 0.53$ & $0.20 \pm 0.17$ & $-0.004 \pm 0.03$ & $0.01 \pm 0.04$ & $0.35 \pm 0.51(0.010 \pm 0.014)$ \\
\hline \multirow[t]{2}{*}{ Sub-Ensemble RCP4.5 } & $-0.31 \pm 0.40$ & $0.10 \pm 0.09$ & $-0.02 \pm 0.03$ & $0.005 \pm 0.010$ & $0.10 \pm 0.16(0.003 \pm 0.004)$ \\
\hline & $\mathrm{G}_{\mathrm{in}}^{\prime} \cdot \Delta \mathrm{S}_{\mathrm{in}}\left(\mathrm{kg} \cdot \mathrm{m}^{-3}\right)$ & $\begin{array}{l}\mathrm{G}_{\text {out }}^{\prime} \cdot \Delta \mathrm{S}_{\text {out }} \\
\left(\mathrm{kg} \cdot \mathrm{m}^{-3}\right)\end{array}$ & $\begin{array}{l}\Delta \mathrm{G}_{\mathrm{in}} \cdot \mathrm{S}_{\mathrm{in}}^{\prime} \\
\left(\mathrm{kg} \cdot \mathrm{m}^{-3}\right)\end{array}$ & $\begin{array}{l}\Delta \mathrm{G}_{\text {out }} \cdot \mathrm{S}^{\prime}{ }_{\text {out }} \\
\left(\mathrm{kg} \cdot \mathrm{m}^{-3}\right)\end{array}$ & \\
\hline Ensemble RCP8.5 & $-0.4 \pm 0.6$ & $-0.1 \pm 0.2$ & $-0.2 \pm 1$ & $0.5 \pm 2$ & \\
\hline Ensemble RCP4.5 & $-0.3 \pm 0.3$ & $-0.1 \pm 0.1$ & $-0.6 \pm 0.9$ & $0.2 \pm 0.4$ & \\
\hline Sub-Ensemble RCP8.5 & $-0.5 \pm 0.5$ & $0.2 \pm 0.1$ & $0.2 \pm 1$ & $0.5 \pm 2$ & \\
\hline Sub-Ensemble RCP4.5 & $-0.3 \pm 0.4$ & $0.08 \pm 0.07$ & $-0.6 \pm 0.9$ & $0.2 \pm 0.4$ & \\
\hline
\end{tabular}
salinity is the result of the salinization of the intermediate

Table 7 Changes in the salinity and volume transport of the inflow $\left(\Delta \mathrm{S}_{\text {in }} /\left(\Delta \mathrm{G}_{\text {in }}\right)\right)$ and outflow $\left(\Delta \mathrm{S}_{\text {out }} / \Delta \mathrm{G}_{\text {out }}\right)$ waters of the Strait of Gibraltar, estimated as the difference between the average of last years of the historical run (1980-2005) and the projection (2075-2100)

The ensemble and sub-ensemble spreads ( \pm standard deviation) are also included. The last four rows are the contribution of the salinity and transport anomalies to the change in the salt content of the basin, as developed in Eq. (4). They have been computed assuming constant values of the inflow/outflow transport ( $G^{\prime}$ in $=0.8 \mathrm{~Sv}, \mathrm{G}^{\prime}$ out $=-0.75 \mathrm{~Sv}$ ) and salinity ( $\mathrm{S}^{\prime} \mathrm{in}=36 \mathrm{psu}$, $\mathrm{S}^{\prime}$ out $=38 \mathrm{psu}$ ) (see text for details) 
and deep waters previously described. These two effects combined (the freshening of the Atlantic inflow and the salting of the Mediterranean outflow) contribute to the loss of salt in the basin.

The other factor to be considered is the change in the water transport through Gibraltar. In those cases where there is an increase in the inflow (or decrease in the outflow), that would translate into a positive contribution to the basin salinization. Unfortunately, here the results must be taken with caution because the computation of water fluxes at the Strait is not straightforward and computing them offline may induce inaccuracies. Only for the CNRMs simulations the computations have been done online and can be considered accurate. Nevertheless, the results are presented here for completeness. On average, the inflow is reduced, $-0.004 \mathrm{~Sv}$ for RCP 8.5 ensemble and $-0.02 \mathrm{~Sv}$ for RCP 4.5, but for some simulations the reduction is much stronger ( $-0.05 \mathrm{~Sv}$ for AWI25-MPI-8.5 and -0.04 Sv for JRC-EC-4.5) while for others the inflow increases $(0.03 \mathrm{~Sv}$ for CNRM-CNRM-8.5) (Table 7). For the outflow, on average an increase of $0.013 \mathrm{~Sv}$ is obtained for the RCP 8.5 runs and $0.005 \mathrm{~Sv}$ for the RCP 4.5 runs (Table 7). The highest positive values are found for JRC-MPI-RCP8.5 simulation $(0.060 \mathrm{~Sv})$ and the lowest for AWI50-MPI-8.5 (-0.050 Sv).

To show the relative contribution of each term to the salt content evolution of the basin we translate it to $\Delta S$ putting the values in Eq. (4). In order to make the comparisons clearer we assume a typical exchange characteristics of Gin' $=0.8 \mathrm{~Sv}$, Gout' $=0.75 \mathrm{~Sv}, \mathrm{~S}_{\text {in }}{ }^{\prime}=36$ and $\mathrm{S}_{\text {out }}{ }^{\prime}=38 \mathrm{psu}$. The results are not expected to be accurate because we do not have the data for all the simulations or, when available, the time resolution is not high enough to obtain a correct closure of the budgets, but a qualitative approximation of the weight of each term in the balance can be obtained. Taking into account this limitations, we see that the most important terms are (see Table 7), on one hand, the freshening of the Atlantic waters comprising the inflow, which contributes to the reduction of the basin salinity, and, on the other hand, the reduction of the outflow volume transport, which increase the salinity of the basin. The salting of the Mediterranean outflow and the reduction of the inflow transport play a secondary role, although not negligible.

\section{Mediterranean water masses and deep convection}

\subsection{Evolution of the main water masses of the Mediterranean}

Another way to look at the thermohaline evolution of the Mediterranean is to focus on the properties of certain water masses. This is motivated by the fact that there is a close relationship between their properties and the diversity of the marine ecosystem present in the basin (Jordà et al. 2012; Marbà et al. 2016). It is important not only from the ecological point of view, the economic exploitation of the fishery resources could be also affected by the changes in the water masses of the basin (Massutí et al. 2008).

In order to assess the evolution of the Mediterranean water masses projected by the models the average TS diagrams of the Western and Eastern basins for the historical runs (1980-2005) and the end of the twenty-first century (2075-2100) are presented in Fig. 8. The figure also shows the histograms of the mean density change between the same periods for the surface, intermediate and deep layers under the RCP8.5 scenario (the outlier simulations have been excluded from the average $\mathrm{T} / \mathrm{S}$ computation and are noted by discolored bars in the histograms). The first result worth to point out is the difference in the evolution of the Western and Eastern basins. In the Western Mediterranean the projected TS diagram show a displacement of the surface layer to warmer waters while keeping the salinity range, which translates in a lightening of the upper layer. Also, there is a shifting and stretching of the intermediate and deep layers to saltier and warmer positions, drastically changing its original shape. On average, the density decreases in the whole water column for all the simulations (except for UBEL-MPI-8.5 that have bias problems in the intermediate and deep layers). On the other hand, the TS diagram of the Eastern Mediterranean is almost uniformly shifted to warmer and saltier positions. The density of the upper and intermediate layers decrease and a small increase is observed in the deeper layer.

Furthermore, we can assess how these changes modify the amount and position of the characteristic water masses of the basin as they are defined at present. To answer this question, we have computed the evolution of the Mediterranean water masses volume along the simulated period. We have considered four principal water masses: the Levantine Intermediate Water (LIW), the Western Intermediate Water (WIW), the Western Mediterranean Deep Water (WMDW) and the Eastern Mediterranean Deep Water (EMDW). The LIW is defined as the water with maximum salinity in the intermediate layer of the Levantine basin (Millot 2014). The WIW is the water of minimum temperature during the winter in the intermediate layer of the Balearic Sea area that is immediately above the LIW (Monserrat et al. 2008). The WMDW and EMDW are defined as those with the minimum of temperature in the deeper layer of the Western and Eastern basins respectively (Roether and Schlitzer 1991; Marshall and Schott 1999). According to these definitions (within an interval of $\pm 0.2{ }^{\circ} \mathrm{C} / \mathrm{psu}$ for the intermediate waters and $\pm 0.1{ }^{\circ} \mathrm{C} / \mathrm{psu}$ for the deep waters) we have identified the $\mathrm{T} / \mathrm{S}$ range corresponding to each water mass in the historical period. This has been done for each model separately because model biases shift the characteristic range of 

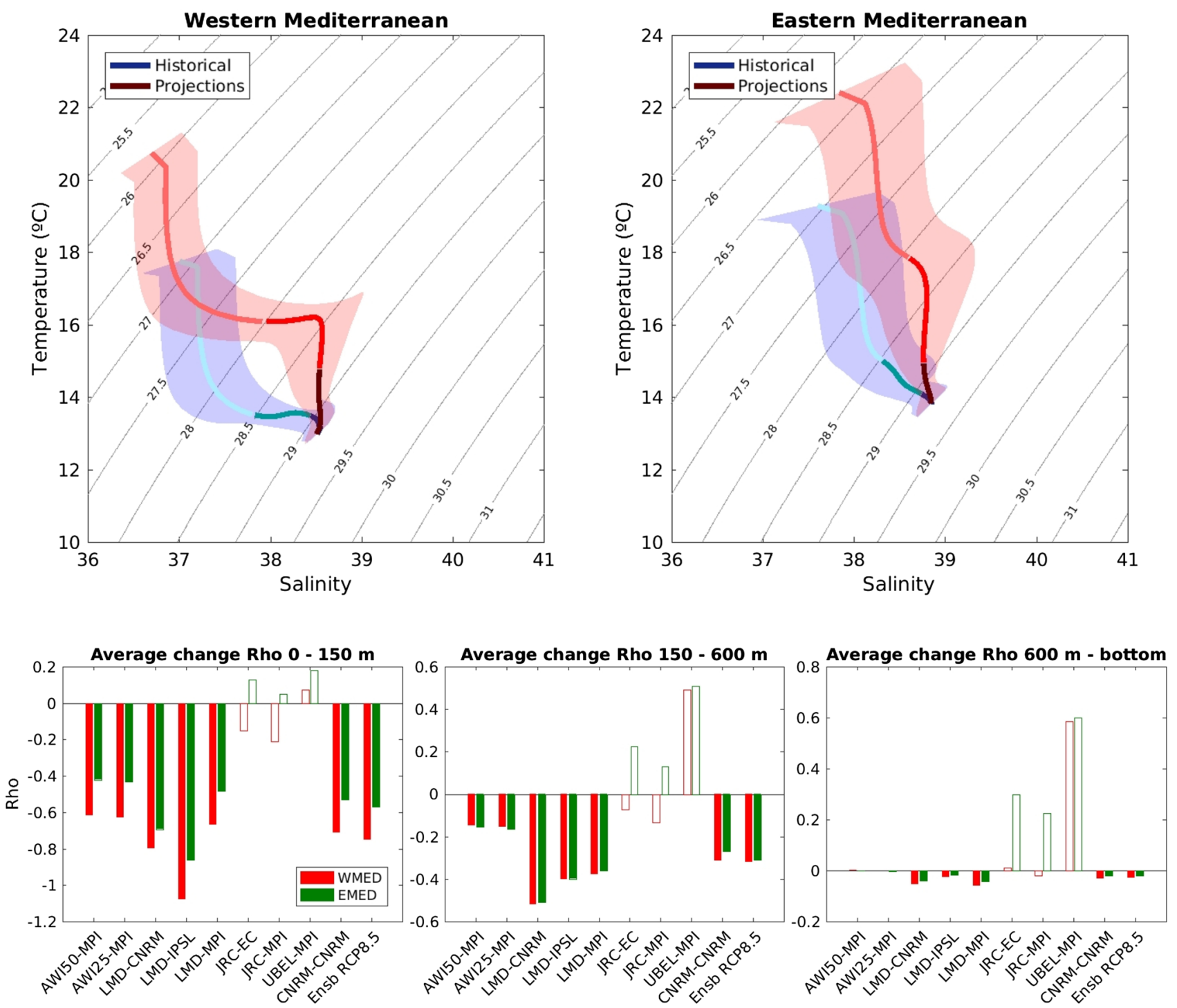

Fig. 8 Average TS diagram of the RCP 8.5 runs for the present (1980-2005) (blue) and future (2075-2100) (red) climates at the Western (left panel) and the Eastern (right panel) Mediterranean. The intensity of the color bar indicates the layer. The shaded areas are the ensemble spread. The histograms represent the average density anomalies $\left(\mathrm{kg} / \mathrm{m}^{3}\right)$ between the future and the present at each layer for the Western (red) and Eastern (green) basins. The discolored bars indicate the simulations with anomalous drifts (see text). These simulations are not considered in the computation of the average T/S diagram

be between 20 and $60 \%$ lower on average. The mean volume of WMDW drastically reduced between 65 and $85 \%$ and the reduction of the EMDW will range between 65 and $60 \%$. For LMDs and CNRMs simulations this reduction reaches $100 \%$ of the present volume. The way to read these results is that the changes in the T/S properties of the water column previously discussed will lead to a change in the characteristics of the main water masses of the basin. In other words, the reduction of the volume of the water masses defined with the current ranges means that the ranges of values characterizing the new water masses will evolve in time. Thus, the ranges that traditionally identify LIW, WIW, WMDW and EMDW 
Table 8 Relative change (in \%) of water masses volume

\begin{tabular}{lllll}
\hline Model & LIW & WIW & WMDW & EMDW \\
\hline AWI50-MPI-8.5 & +30.63 & -43.12 & -63.04 & -96.17 \\
AWI50-MPI-4.5 & +186.25 & -62.93 & -43.82 & -39.30 \\
AWI25-MPI-8.5 & +50.03 & -31.20 & -71.77 & -99.42 \\
LMD-CNRM-8.5 & -100.00 & -46.36 & -100.00 & -100.00 \\
LMD-IPSL-8.5 & -99.81 & +83.33 & -100.00 & -99.73 \\
LMD-MPI-8.5 & -100.00 & -69.76 & -100.00 & -100.00 \\
JRC-EC-4.5 & -19.49 & -7.15 & -37.92 & -14.78 \\
JRC-EC-8.5 & 13.20 & -57.04 & -87.43 & -7.63 \\
JRC-MPI-4.5 & -6.30 & -55.15 & -83.57 & +8.78 \\
JRC-MPI-8.5 & +64.72 & -98.38 & -99.32 & 39.97 \\
UBEL-MPI-8.5 & -28.16 & -15.46 & -86.74 & -94.78 \\
ENEA-CNRM-4.5 & -75.54 & +172.62 & -67.72 & +21.01 \\
CNRM-CNRM-8.5 & -99.25 & -99.99 & -100.00 & -98.02 \\
CNRM-CNRM-4.5 & -97.35 & -30.39 & -100.00 & -97.48 \\
CNRM-CNRM-2.6 & -97.75 & +94.88 & -100.00 & -94.96 \\
EnsembleRCP85 & $-35.11 \pm 68.50$ & $-21.14 \pm 85.23$ & $-87.70 \pm 14.91$ & $-60.00 \pm 56.16$ \\
Ensemble RCP45 & $+6.99 \pm 95.01$ & $-34.21 \pm 21.73$ & $-70.41 \pm 24.81$ & $-47.51 \pm 42.52$ \\
Sub-Ensemble RCP8.5 & $+11.87 \pm 58.22$ & $-65.94 \pm 28.35$ & $-84.31 \pm 14.77$ & $-52.26 \pm 57.87$ \\
Sub-Ensemble RCP4.5 & $+15.78 \pm 104.39$ & $-38.90 \pm 21.92$ & $-66.33 \pm 26.19$ & $-35.70 \pm 39.51$ \\
\hline
\end{tabular}

A positive value means an increase of the specific water mass volume by the end of the twenty-first century (2075-2100) with respect to the present climate (1980-2005), and vice versa. Note that here the characteristics of the water masses are set fixed to the present climate values should also evolve in time. The projections analyzed here suggest that new water masses will be warmer, saltier and less dense (in general) than the current ones.

\subsection{Deep water formation}

Another important process to be analyzed in order to understand the evolution of the Mediterranean water properties is the deep water formation. As a proxy of the amount of deep water formed every annual cycle, we have considered the annual maximum of the mixed layer depth (MLD). We have used a temperature criterion to define the MLD with a threshold of $0.4{ }^{\circ} \mathrm{C}$ (other thresholds have been tested leading to the same conclusions). The computations have been performed on the monthly temperature fields as these are the fields available for all the simulations. However, in order to test the robustness of the results we have computed also the maximum MLD using daily fields for the CNRM runs. The results show that the conclusions are insensitive to the use of daily or monthly fields.

Table 9 summarizes the yearly maximum MLD averaged for the present and future climates (and its difference) for each simulation. The histograms of the max MLD for present and future climate under the RCP8.5 scenario are represented in Figures S18-S20. The computation has been performed in the Gulf of Lions, the Adriatic Sea and the
Aegean Sea, the main spots for deep water formation in the Mediterranean.

In the Gulf of Lions, the averaged maximum MLD ranges for the present climate is very diverse with values ranging from of $182 \mathrm{~m}$ in UBEL-MPI-8.5 to values larger than $2000 \mathrm{~m}$ in JRC and AWI runs. In any case all the simulations (except ENEA-CNRM-4.5) show a clear reduction in the averaged maximum MLD, being larger under scenario RCP8.5 (Table 9). The reduction is also very different among simulations, ranging between almost $90 \%$ for AWI runs and $20 \%$ for some LMD runs. In the Adriatic Sea, the maximum MLD in the present climate also shows a wide range depending on the simulation, between $91 \mathrm{~m}$ for UBEL-MPI-8.5 and around $1000 \mathrm{~m}$ for IPSL-IPSL-8.5 and ENEA-MPI-4.5 runs. In this region a majority of simulations project a reduction in the maximum MLD but smaller than in the Gulf of Lions, ranging between 2 and $45 \%$. Nonetheless, a few runs project a small increase in this area (CNRMs, LMD-CNRM-8.5 and LMD-MPI-8.5) (Table 9). In the Aegean Sea, the projected variability of the maximum MLD is lower than in the other two DWF regions. In the present climate, it varies between 220 and $868 \mathrm{~m}$ for UBEL-MPI- 8.5 and JRC-EC runs respectively. Most simulations project a reduction that do not exceed $20 \%$ in any case, although a few runs point to a slightly increase $(<8 \%)$ (Table 9$)$. In summary, the results suggest changes in the intensity of the deep water formation in the main formation areas, with a projected decrease in 
Table 9 Maximum Mix Layer Depth (MLD) ( \pm standard deviation) for the present climate (1980-2005), the future climate (2075-2100) and their difference at the DWF spots of the Western and Eastern Mediterranean

\begin{tabular}{|c|c|c|c|c|c|c|c|c|c|}
\hline \multirow[t]{2}{*}{ Model } & \multicolumn{3}{|c|}{ Gulf of Lions } & \multicolumn{3}{|c|}{ Adriatic Sea } & \multicolumn{3}{|c|}{ Aegean Sea } \\
\hline & Present & Future & Difference & Present & Future & Difference & Present & Future & Difference \\
\hline AWI50-MPI-8.5 & $2100 \pm 558$ & $243 \pm 56$ & $-1848 \pm 570$ & $786 \pm 175$ & $467 \pm 114$ & $-319 \pm 191$ & $640 \pm 190$ & $572 \pm 94$ & $-68 \pm 201$ \\
\hline AWI50-MPI-4.5 & $2091 \pm 558$ & $429 \pm 164$ & $-1662 \pm 378$ & $786 \pm 175$ & $642 \pm 234$ & $-144 \pm 277$ & $640 \pm 190$ & $608 \pm 174$ & $-32 \pm 228$ \\
\hline AWI25-MPI-8.5 & $2043 \pm 651$ & $222 \pm 47$ & $-1821 \pm 657$ & $795 \pm 191$ & $451 \pm 115$ & $-344 \pm 201$ & $664 \pm 184$ & $557 \pm 107$ & $-107 \pm 195$ \\
\hline LMD-CNRM-8.5 & $334 \pm 62$ & $273 \pm 41$ & $-60 \pm 81$ & $156 \pm 47$ & $207 \pm 74$ & $51 \pm 81$ & $416 \pm 71$ & $422 \pm 86$ & $6 \pm 111$ \\
\hline LMD-IPSL-8.5 & $1300 \pm 919$ & $209 \pm 29$ & $-1091 \pm 920$ & $994 \pm 265$ & $539 \pm 69$ & $-455 \pm 276$ & $760 \pm 467$ & $587 \pm 128$ & $-173 \pm 477$ \\
\hline LMD-MPI-8.5 & $361 \pm 90$ & $269 \pm 40$ & $-92 \pm 94$ & $200 \pm 77$ & $281 \pm 99$ & $80 \pm 113$ & $448 \pm 94$ & $489 \pm 135$ & $41 \pm 195$ \\
\hline JRC-EC-4.5 & $2167 \pm 548$ & $1079 \pm 239$ & $-1088 \pm 625$ & $592 \pm 76$ & $570 \pm 80$ & $-14 \pm 94$ & $868 \pm 208$ & $876 \pm 158$ & $9 \pm 203$ \\
\hline JRC-EC-8.5 & $2167 \pm 548$ & $798 \pm 170$ & $-1368 \pm 587$ & $592 \pm 76$ & $544 \pm 82$ & $-48 \pm 127$ & $868 \pm 208$ & $862 \pm 167$ & $-5 \pm 285$ \\
\hline JRC-MPI-4.5 & $2138 \pm 507$ & $1108 \pm 279$ & $-1032 \pm 555$ & $669 \pm 103$ & $624 \pm 58$ & $-45 \pm 121$ & $820 \pm 234$ & $884 \pm 151$ & $64 \pm 83$ \\
\hline JRC-MPI-8.5 & $2138 \pm 507$ & $787 \pm 148$ & $-1352 \pm 507$ & $669 \pm 103$ & $593 \pm 72$ & $-76 \pm 128$ & $820 \pm 234$ & $829 \pm 118$ & $8 \pm 267$ \\
\hline UBEL-MPI-8.5 & $182 \pm 23$ & $132 \pm 19$ & $-50 \pm 32$ & $91 \pm 11$ & $79 \pm 10$ & $-13 \pm 12$ & $220 \pm 33$ & $194 \pm 26$ & $-26 \pm 45$ \\
\hline ENEA-CNRM-4.5 & $828 \pm 440$ & $2735 \pm 308$ & $1926 \pm 641$ & $967 \pm 189$ & $892 \pm 128$ & $-74 \pm 200$ & $796 \pm 235$ & $667 \pm 137$ & $-129 \pm 274$ \\
\hline CNRM-CNRM-8.5 & $790 \pm 573$ & $233 \pm 47$ & $-557 \pm 578$ & $247 \pm 122$ & $312 \pm 11$ & $65 \pm 144$ & $510 \pm 154$ & $426 \pm 105$ & $-85 \pm 197$ \\
\hline CNRM-CNRM-4.5 & $790 \pm 573$ & $337 \pm 147$ & $-453 \pm 635$ & $247 \pm 122$ & $256 \pm 97$ & $9 \pm 166$ & $510 \pm 154$ & $467 \pm 128$ & $-43 \pm 178$ \\
\hline CNRM-CNRM-2.6 & $790 \pm 573$ & $461 \pm 190$ & $-328 \pm 634$ & $247 \pm 122$ & $323 \pm 146$ & $75 \pm 175$ & $510 \pm 154$ & $530 \pm 168$ & $20 \pm 234$ \\
\hline
\end{tabular}

the Gulf of Lions, while no robust results are found for the Adriatic and the Aegean seas.

\section{Discussion}

\subsection{Warming and heat budget change}

The fifteen projections included in the ensemble agree in predicting an increase of the SST of the Mediterranean, ranging between 0.86 and $3.73{ }^{\circ} \mathrm{C}$ on average (Fig. 2; Table 3 ). We find that the warming is strongly dependent on the choice of emission scenario, with a difference of $1.12{ }^{\circ} \mathrm{C}$ between the average of the sub-ensembles RCP 8.5 and the RCP 4.5. More precisely we have four couples of simulations run with the same modeling system for both scenarios. Comparing them we find that under RCP8.5 the warming is $1.43{ }^{\circ} \mathrm{C}, 1.17{ }^{\circ} \mathrm{C}, 0.80^{\circ} \mathrm{C}$ and $1.17^{\circ} \mathrm{C}$ higher than under the RCP4.5 in AWIs, CNRMs and JRCs runs, respectively. Adloff et al. (2015) carried out a multi-scenario study using several configurations of the same regional climate model and also found that the choice of scenario is the key factor in the evolution of the SST. Darmaraki et al. (2019) using a different Med-CORDEX ensemble also reported similar results.

In addition, we identify the choice of global model as the second influential factor determining the mean SST increase. Significant difference can be observed between simulations which only differ in the global model selection. For instance, the anomaly in the LMD simulation using IPSL-CM5A-MR model is 25\% warmer than for the one using CNRM-CM5.
Among the JRC simulations, those using EC-Earth are 20\% and $10 \%$ warmer than the ones using MPI-ESM-MR for the RCP 8.5 and RCP 4.5 scenarios, respectively (Table 3). This influence, however, is reflected only in the average value, whereas the spatial distribution of the warming is clearly determined by the regional model. A quantitative approximation to illustrate this point is obtained computing the spatial correlation between the different simulations (Figure S16). When we compare the pattern of change we see that high correlations are obtained between the simulations of the same family and relatively low correlations are obtained between simulations of different families. Even though simulations of the same family use different global models (i.e. LMDs, JRCs) or different atmospheric model resolution (AWIs), the spatial correlation is always higher between them than with other simulations. This means that the local structures reproduced by each simulation are strongly dependent on the regional model and not on the scenario or the global model. Nonetheless, the areas showing higher warming coincide (North Adriatic, Balearic Sea, Levantine basin and North Aegean), and agree with the previous results of Adloff et al. (2015) and Darmaraki et al. (2019), who also find average anomalies in the same range of our estimations ([1.73-2.97] ${ }^{\circ} \mathrm{C}$ for the former and $[1.9-3.6]{ }^{\circ} \mathrm{C}$ for the latter). In contrast, in Somot et al. (2006) the authors found a quite homogeneous SST increase of $\sim 3.1{ }^{\circ} \mathrm{C}$ for the whole basin that they attribute to the relaxation term applied to the SST of the coarsely resolved GCM.

The increase of the SST is transferred to the deeper layers, resulting in a general warming of the water column particularly noticeable in the upper and intermediate layers 
(Fig. 3; Table 3). In the upper layer we find good agreement among simulations and, as for the SST, the main difference comes from the choice of scenario $\left(2.44{ }^{\circ} \mathrm{C}\right.$ in RCP8.5 vs. $1.30{ }^{\circ} \mathrm{C}$ in RCP 4.5 on average).

In the intermediate and deeper layers the warming is also present, although reduced. Then, models with strange behavior in those layers can contaminate the ensemble average. For instance, UBEL-MPI-8.5 shows negative biases, while ENEA-CNRM-4.5 and JRCs show abnormally high anomalies, especially in the deeper layer. As reported in Sect. 2.1, these problems were already present in the historical runs of these simulations and hence expected to persist in the projections (Fig. S11). Our main hypothesis is that a too short spin-up could have induced this bias in the deep layer as far as a stable state of the basin thermohaline circulation was not achieved before starting the simulations. In the case of UBEL-MPI-8.5, in addition to the spin-up problem, the low resolution of the ocean model might have limited its ability to resolve the vertical processes of the basin. Taking into account all these considerations, the results are similar to those obtained by Adloff et al. (2015) in the upper and intermediate layers, but not in the deep layer, where the authors find anomalies higher than our estimations.

To illustrate how the warming of the surface layer is transported to the deeper layers, we show in Fig. 9 the SST anomalies against the anomalies of the upper, intermediate and deep layers. We see that in the first $150 \mathrm{~m}$ the relation is almost linear for all the simulations, $\left(r^{2}=0.90\right)$, suggesting that the heat gained at the surface is effectively transported to this layer. In the intermediate layer, if UBEL-MPI- 8.5 is not considered, the correlation is also high $\left(\mathrm{r}^{2}=0.78 ; 0.29\right.$ if UBEL-MPI-8.5 is included). Conversely, in the deep layer AWIs, LMDs and CNRMs simulations show very low temperature anomalies and the linear relation with the SST is lost. Conversely, JRCs and ENEA-CNRM-4.5 maintain the linear relation with the SST $\left(r^{2}=0.95\right.$ if only those runs are considered), meaning that in these simulations the heat gain at the surface is transported along the whole water column and reaches the bottom. This results reinforces the hypothesis that in these simulations the lack of a long enough spinup has prevented a stable stationary state to be reached in the deeper layer.

On the other hand, the warming projected by AWIs, LMDs and CNRMs simulations in the deep layer is very low. A recent study by Artale et al. (2018) based on CTD observations over the Ionian Sea shows a progressive increase in the temperature of the abyssal Ionian (below $2000 \mathrm{~m}$ ) of around $0.2^{\circ} \mathrm{C}$ between 1977 and 2011. This warming entails a heat storage in the deepest layer of the eastern Mediterranean of around $1.6 \mathrm{~W} / \mathrm{m}^{2}$. They conclude that the coexisting stable stratification, deep mixing, intense meridional overturning circulation and mesoscale eddies affect the heat content redistribution within the Eastern Mediterranean abyss. These results confirm similar observations in the global ocean (de Lavergne et al. 2016; Ferrari et al. 2016). Unfortunately, neither the historical runs nor the projections of the Med-CORDEX simulations with stable initial conditions show any significant warming below $1500 \mathrm{~m}$ in the Eastern Mediterranean (figure not shown). This suggests that the existing simulations are unable to reproduce the mechanisms that transfer heat and salt to the abyssal layers.

Through the heat budget analysis we conclude that the heat gain of the basin during the twenty-first century is the result of the reduction of the heat losses from the sea to the atmosphere, or in other words, the increase of the net heat input. This heat gain is variable among simulations, ranging between 0.71 and $5.41 \mathrm{~W} / \mathrm{m}^{2}$, with average values of $2.50 \mathrm{~W} / \mathrm{m}^{2}$ and $1.12 \mathrm{~W} / \mathrm{m}^{2}$ for the RCP 8.5 and RCP $4.5 \mathrm{sub}-$ ensembles, respectively (Table 5). These values agree with all the previous estimations for the basin (Somot et al. 2006; Dubois et al. 2012; Adloff et al. 2015). The contribution of the heat input through the Strait of Gibraltar in the basin heat content change is on average one order of magnitude smaller
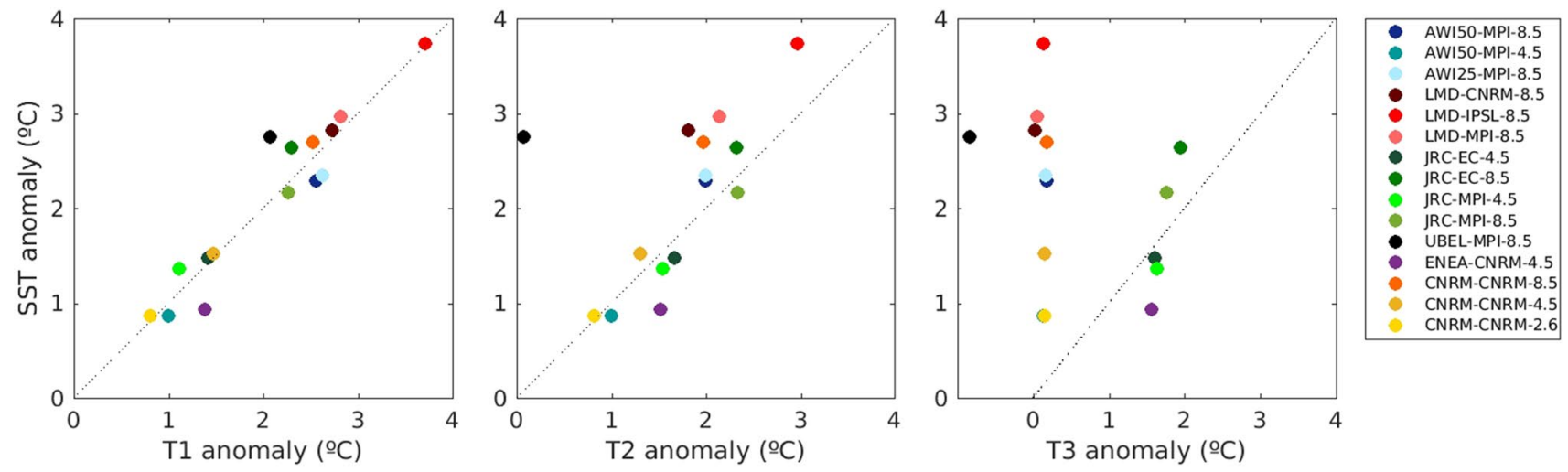

Fig. 9 Scatter plots of the average SST anomalies against the average temperature anomalies at the upper (T1), intermediate (T2) and deep layers (T3). In degrees Celsius $\left({ }^{\circ} \mathrm{C}\right)$ 
than the surface flux term, although in some simulations it can be quite important. This is the case of the AWI simulations, in which the reduction of the Strait net heat transport modulates the basin heat gain, reducing it in almost 50\% with respect to the surface flux contribution. In that case, this is caused by the warm outflow through Gibraltar, which is higher than the warming of the upper layer.

Another result worth discussing is that for some simulations (JRCs, ENEA-CNRM-4.5 and CNRM-CNRM-2.6) the $\mathrm{HCC}$ is slower in the projection with respect to the historical period (i.e. there is a deceleration of the warming). The strong temperature trends in the intermediate (in JRCs) and deep (in JRCs and ENEA-CNRM-8.5) layers of the historical runs are the likely cause of this deceleration. The warming in these simulations is the result of the sum of two terms: the drift caused by the lack of a long enough spin-up and the warming induced by the GHG. The first term is stronger at the beginning of the simulation, but as the model progresses towards a steady state this term is reduced. The global effect is that the warming in the beginning of the simulation is faster than at the end, which is translated into a net deceleration over the complete period.

\subsection{Salting and salt budget change}

The general behavior of all the simulations is towards a salinization of the basin, mainly induced by an increase in the freshwater deficit through the sea surface. All simulations show an increase of the water losses in the basin varying from 0.14 to $0.83 \mathrm{~mm} /$ day (Table 6), in good agreement with those reported in previous works (Somot et al. 2006; Dubois et al. 2012; Adloff et al. 2015). That water loss is partly compensated by an increase of the net flow through

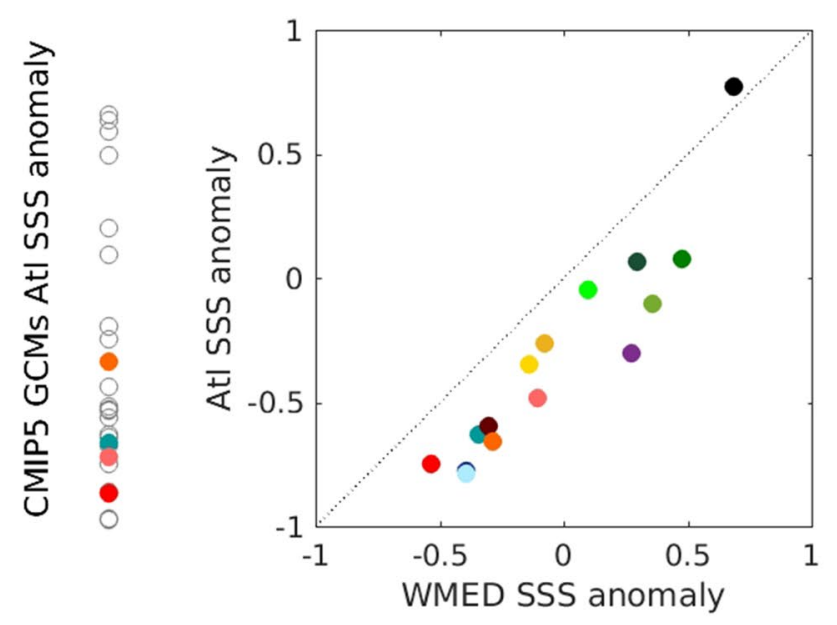

Fig. 10 Scatter plots of the average SSS anomalies (psu) at the Atlantic area of the different models domain for each simulation against the average SSS anomalies at the Western (left panel) and Eastern (right the Strait of Gibraltar, thus replacing the evaporated (fresh) water by salty water.

However, if we look at the behavior at different layers a more complex picture arises. First, changes in the SSS by the end of the century are very different than those obtained for the SST. Its evolution is characterized by a strong positive longitudinal gradient towards the East (Fig. 5). All simulations show larger increases in the eastern basin than in the western basin where only a few simulations show positive values (JRCs, UBEL-MPI-8.5), the rest having close to zero or negative values. Considering the basin average the SSS anomaly oscillate between -0.25 psu for AWI50-MPI-4.5 and +0.88 psu for UBEL-MPI- 8.5 , thus not all the simulations project a saltier Mediterranean Sea surface by the end of the century (Table 6). This result contradicts previous studies, which found a positive mean salinity anomaly for the basin (Somot et al. 2006; Adloff et al. 2015). However, a likely explanation of the negative values of this study was already discussed in the latter reference. The authors pointed out that the change in Atlantic boundary conditions is the most sensitive factor in the SSS evolution. To confirm this extent, Fig. 10 shows the relation between anomalies in the Atlantic SSS (at the entrance of the Strait of Gibraltar) and in the western/eastern basins. In the Western Mediterranean we see an almost perfect correlation (0.95) in all the simulations, while in the east the correlation decreases to 0.80 which is still high. In both basins the SSS anomalies are larger than in the Atlantic meaning that the Mediterranean evolution is affected by the Atlantic conditions but not exclusively. Also, the effects of the Atlantic surface waters are reduced in the eastern basin compared to the western basin, which was expected as the basin is further away from the Strait. Thus, our explanation for the SSS behavior in the Mediterranean is that the increase of water deficit over

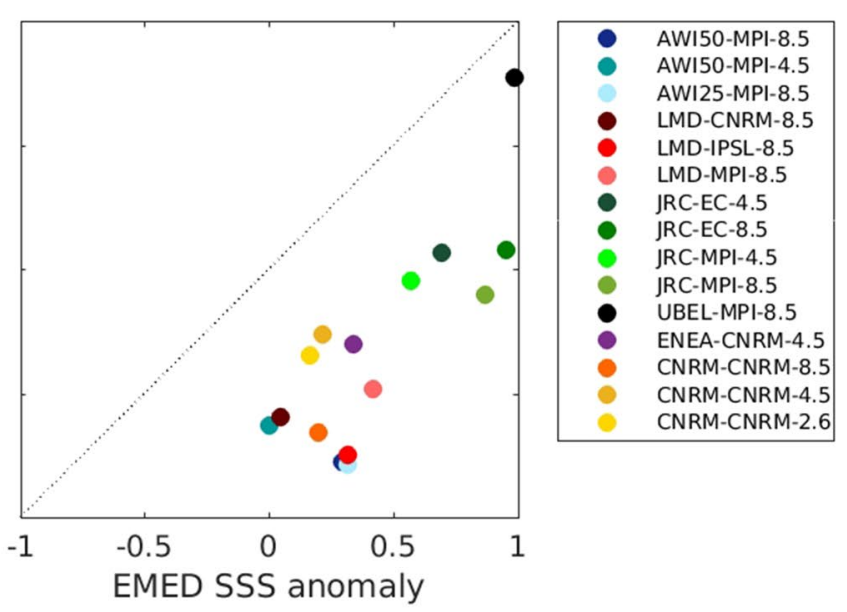

panel) Mediterranean. On the left, the SSS anomalies at the Atlantic for 25 different GCM of the CMIP5. The colors identify the GCMs used by the simulations of the ensemble 
the basin would increase the SSS, while the characteristics of the Atlantic waters inflowing in the Mediterranean may enhance or damp that increase depending on their characteristics. Furthermore, it is worth noting the large spread among GCMS (i.e. Atlantic conditions). This suggests that different models advect the fresher waters from the Arctic following different paths, and in some cases they may arrive close the Iberian Peninsula and thus affect the waters entering into the Mediterranean, as seen by Gomis et al. (2016).

Another interesting question to add to this analysis is if the GCMs used in the Med-CORDEX ensemble are representative of the whole range of values in the CMIP5 ensemble. Figure 10 includes the SSS anomaly in the Atlantic domain for 25 CMIP5 GCMs, including four of the five GCMs used by the Med-CORDEX ensemble (the EC-Earth model used by JRC was not included). For most of the GCMs the SSS anomaly is negative (19 out of 25). The median of CMIP5 Atlantic SSS anomalies is $-0.53 \mathrm{psu}$, while in our ensemble is $-0.69 \mathrm{psu}$. Also the range of values is well represented in the Med-CORDEX ensemble with Atlantic anomalies ranging from -0.75 to $0.89 \mathrm{psu}$, while in the CMIP5 ensemble the range is from -0.87 to +0.73 psu. Therefore, the GCM sub-selection made in Med-CORDEX can be considered as representative of a wide range of values produced by the full CMIP5 ensemble. However, none of the CMIP5 GCMs with positive SSS anomalies are used so part of the uncertainties related to the future evolution of the Atlantic Ocean salinity is missing. Future simulations should include some of these GCMs to complete the analysis of the effect of the GCM selection.

The effect of the Atlantic fresh anomalies is still present in the upper layer of the Western basin, but for the whole basin the average anomalies are positive in most simulations, with a mean increase of 0.34 psu for RCP8.5 runs and $0.25 \mathrm{psu}$ for RCP4.5 (Table 5). In the intermediate layer all the simulations (except LMD-CNRM-8.5) show positive anomalies in both sub-basins (average of 0.50 psu for RCP8.5 and 0.39 psu for RCP 4.5 runs). It is in this layer where the increase of salinity is more marked. In the deep layer there is also a general increase (average of $0.32 \mathrm{psu}$ for RCP 8.5 and 0.37 psu for RCP4.5 runs), but the positive drifts of JRC and UBEL-POM simulations have to be considered. If we remove these simulations the average change is reduced by almost $80 \%$.

\subsection{Changes in the water masses}

The previous results are directly translated to the modification of the water masses properties of the basin. If we not consider the outliers, a general reduction of the density is expected in the whole water column, in agreement with the results of Somot et al. (2006) but in contrast with the findings of Adloff et al. (2015) (Fig. 8). Since both studies underline the sensitivity of this parameter to the experiment set-up the discrepancies in the results are expected. The important point is that the $\mathrm{T} / \mathrm{S}$ characteristics of the main water Mediterranean water masses as we currently define them will be modified. By the end of the century most of the "present" water masses will have been replaced by new ones with different characteristics (saltier, warmer and less dense) (Table 8).This may translate in impacts to Mediterranean marine ecosystems (Jordà et al. 2012; Marbà et al. 2016) and in consequence to fisheries (Massutí et al. 2008; Amores et al. 2014).

Regarding the deep water formation, the estimation based on the maximum mixed layer depth described in Sect. 5.2 suggests a clear reduction in the intensity of the dense water formation, with most models pointing in that direction. This is projected to happen in the three main regions of formation, with larger changes linked to scenarios with larger GHG emissions. This is in good agreement with previous studies (Somot et al. 2006; Adloff et al. 2015). Both works found a reduction in the production of WMDW in the area due to an increase of the stratification which in turn imply a decrease of the thermohaline circulation intensity in the region. Somot et al. (2006) attributed that reduction to the density decrease of the newly formed deep water, which would be too light to reach the deeper layers. This does not seem to be our case since the density change we find in the deeper layer is very low in comparison. On the other hand, Adloff et al. (2015) found a small increase in the deep water density $\left(\sim+0.05 \mathrm{~kg} / \mathrm{m}^{3}\right)$ but a significant reduction in the intensity of the convective cell, which may be the result of an enhanced stratification in the upper layer. Our results would point to that explanation.

In the Adriatic, most models agree in projecting a reduction in the intensity of the deep convection events (Fig. 9). Somot et al. (2006) found an increase in the deep DWFR in this area, but producing lighter waters that ended up weakening the Eastern Mediterranean thermohaline cell. Adloff et al. (2015) also found a weakening in the intensity of the thermohaline circulation cell of that region, with a small reduction of the deep water production. These authors also found an intensification of the convection in the Aegean Sea for their ASR-B1 scenario simulation, similar to the observed during the Eastern Mediterranean Transient in the decade of 1990 (Roether et al. 1996) which led them to suggest that warming could favor an EMT-like quasi permanent situation. In the Aegean, although the results among models are not as robust as for the other DWF regions, they point towards a reduction of the DWF, so it does not seem likely that an EMT-like situation could be sustained in the future. 


\section{Conclusions}

A large ensemble of Mediterranean regional ocean climate simulations has been analyzed under different climate change scenarios. In particular, the Med-CORDEX ensemble formed by 25 simulations, 10 historical runs and 15 scenario projections. Among the projections, 11 are ocean-atmosphere coupled runs and 4 ocean forced simulations.

All the simulations project a warming of the Mediterranean basin by the end of the twenty-first century as a result of the decrease of heat losses to the atmosphere through the sea surface and an increase in the heat input through the Strait of Gibraltar. This warming will affect the whole water column and its intensity will strongly depend on the emission scenario and, in a second order, on the choice of global model providing the boundary conditions. The projected warming is not homogeneous and the spatial distribution of the warming patterns is determined by the regional climate model used for the simulation. Nonetheless, all models agree in projecting higher warming in the Levantine Basin, North of the Aegean Sea, Adriatic Sea and the Balearic Sea.

Concerning the salinity, all models project an average salinization of the basin driven by the increase in the freshwater deficit. However, in the upper layer this effect could be modified by the characteristics of the inflowing waters from the Atlantic. Most GCMs project a freshening of the Northeast Atlantic waters while some others project an increase in their salinity. This is directly transferred into the Mediterranean modifying the SSS evolution, especially in the western basin. Thus, a clear zonal gradient is found with larger positive anomalies in the eastern basin and the highest values in the Aegean and the Adriatic seas. In the western basin some simulations even project a freshening of the surface waters. In the upper $150 \mathrm{~m}$ the differences between the eastern and western basins persist but below that, in the intermediate and deep layers, no significant differences are found between both basins.

Those changes in the temperature and salinity will in turn modify the characteristics of the main water masses. The new waters will be saltier, warmer and less dense. These changes will in turn affect the ventilation of the basin. The results suggest a decrease in the dense water formation rates in the Gulf of Lions and in the Adriatic, while in the Aegean the results are not robust across the ensemble members.

The results presented here underline the need to improve some aspects of Mediterranean RCSM that should be addressed in the future by the modeling community:

- Regarding the simulation set-up, there is the need of long enough spin-up periods in order to reach a stable stationary state in the deep ocean. Starting the projections from a non-stabilized situation can lead to wrong projections.
A possible criterion could be to stablish a threshold in the temperature and salinity trends of the historical runs that don't exceed the observations. For the same reasons, continuous transient runs should be recommended in order to avoid break and reinitialisation between the historical and the scenario periods.

- The on-line computation and storage of key magnitudes such as the heat, water and mass transports at the Straits of Gibraltar and Sicily, are crucial for an accurate computation of budgets and a better understanding of the projected changes.

- The choice of the GCM to provide boundary forcing should be done carefully. Since the number of GCMs that can be used is limited, the choice should be such that the ensemble spans the range of GCM projections.

- The choice of RCM has also a noticeable impact on some of the diagnostics, so in order to properly cover the whole range of uncertainty it is important to have a sufficient number of GCM-RCM pairs in the ensemble.

Many of these recommendations and the future steps towards the improvement of the climatic simulations in the Mediterranean Sea are being addressed in the phase 2 of the Med-CORDEX initiative (Somot et al. 2018b).

Acknowledgements This work has been carried out in the frame of the Spanish Ministerio de Ciencia, Innovación y Universidades funded CLIFISH Project (CTM2015-66400-C3-2-R). Additional support received from the EU project SOCLIMPACT (This project has received funding from the European Union's Horizon 2020 research and innovation program under grant agreement No 776661). This work is part of the Med-CORDEX initiative (www.medcordex.eu) and HyMeX program (www.hymex.org). DS also acknowledges the state assignment of FASO Russia (theme 0149-2019-0015).

Funding This study was funded by the Spanish Ministerio de Ciencia, Innovación y Universidades funded CLIFISH Project (CTM2015-66400-C3-2-R).

\section{References}

Adloff F, Somot S, Sevault F et al (2015) Mediterranean Sea response to climate change in an ensemble of twenty first century scenarios. Clim Dyn 45:2775-2802. https://doi.org/10.1007/s0038 2-015-2507-3

Amores A, Rueda L, Montserrat S et al (2014) Influence of the hydrodynamic conditions on the accessibility of Aristeus antennatus and other demersal species to the deep water trawl fishery off the Balearic Islands (western Mediterranean). J Mar Sys 138:203210. https://doi.org/10.1016/j.jmarsys.2013.11.014

Artale V, Calmanti S, Carillo A et al (2010) An atmosphere-ocean regional climate modelfor the Mediterranean area: assessment of a presentclimate simulation. Clim Dyn 35:721-740. https://doi. org/10.1007/s00382-009-0691-8

Artale V, Falcini F, Marullo S et al (2018) Linking mixing processes and climate variability to the heat content distribution of the Eastern Mediterranean abyss. Nat Sci Rep 8(1):11317 
Bethoux JP, Gentili B (1999) Functioning of the Mediterranean sea: past and present changes related to freshwater input and climate changes. J Mar Syst 20:33-47. https://doi.org/10.1016/S0924 -7963(98)00069-4

Bethoux JP, Gentili B, Morin P et al (1999) The Mediterranean Sea: a miniature ocean for climatic and environmental studies and a key for the climatic functioning of the North Atlantic. Prog Oceanogr 44:131-146. https://doi.org/10.1016/S0079-6611(99)00023-3

Beuvier J, Béranger K, Brossier CL et al (2012) Spreading of the Western Mediterranean deep water after winter 2005: time scales and deep cyclone transport. J Geophys Res Ocean. https://doi. org/10.1029/2011JC

Beuvier J, Sevault F, Herrmann M et al (2010) Modeling the Mediterranean Sea interannual variability during 1961-2000: focus on the Eastern Mediterranean Transient. J Geophys Res Ocean. https:// doi.org/10.1029/2009JC005950

Darmaraki S, Somot S, Sevault F et al (2019) Future evolution of marine heatwaves in the Mediterranean Sea. Clim Dyn. https:// doi.org/10.1007/s00382-019-04661-z

de Lavergne C, Madec G, Le Sommer J et al (2016) On the consumption of Antarctic bottom water in the abyssal ocean. J Phys Oceanogr 46:635-661

Demirov E, Pinardi N (2002) Simulation of the Mediterranean Sea circulation from\r1979 to 1993: Part I. The interannual variability. J Mar Syst 33-34:23-50. https://doi.org/10.1016/S0924 -7963(02)00051-9

Djurdjevic V, Rajkovic B (2010) Development of the EBU-POM coupled regional climate model and results from climate change experiments. In: Mihajlovic TD, Lalic B (eds) Advances in environmental modeling and measurements. Nova Publishers, Hauppauge, pp 23-32, ISBN: 978-1-60876-599-7

Dubois C, Somot S, Calmanti S et al (2012) Future projections of the surface heat and water budgets of the Mediterranean Sea in an ensemble of coupled atmosphere-ocean regional climate models. Clim Dyn 39:1859-1884. https://doi.org/10.1007/s0038 2-011-1261-4

Escudier R, Renault L, Pascual A et al (2016) Eddy properties in the Western Mediterranean Sea from satellite altimetry and a numerical simulation. J Geophys Res Ocean 121:3990-4006. https://doi. org/10.1002/2015JC011371

Fernández V, Dietrich DE, Haney RL, Tintoré J (2005) Mesoscale, seasonal and interannual variability in the Mediterranean Sea using a numerical ocean model. Prog Oceanogr 66:321-340. https://doi. org/10.1016/j.pocean.2004.07.010

Ferrari R, Mashayek A, McDougall TJ et al (2016) Turning ocean mixing upside down. J Phys Oceanogr 46(7):2239-2261

Giorgi F (2006) Climate change hot-spots. Geophys Res Lett 33:1-4. https://doi.org/10.1029/2006GL025734

Giorgi F, Lionello P (2008) Climate change projections for the Msediterranean region. Glob Planet Change 63:90-104. https://doi. org/10.1016/j.gloplacha.2007.09.005

Gomis D, Alvarez-Fanjul E, Jordà G, et al. (2016) Regional marine climate scenarios in the NE Atlantic sector close to the Spanish shores. Sci Mar 80:215-234. DOI: 10.3989/scimar.04328.07A.

Gualdi S, Somot S, Li L et al (2013) THE circe simulations: resgional climate change projections with realistic representation of the mediterranean sea. Bull Am Meteorol Soc 94:65-81. https://doi. org/10.1175/BAMS-D-11-00136.1

Hamon M, Beuvier J, Somot S et al (2016) Design and validation of MEDRYS, a Mediterranean Sea reanalysis over the period 1992-2013. Ocean Sci 12:577-599. https://doi.org/10.5194/ os-12-577-2016

Harzallah A, Jordà G, Dubois C et al (2018) Long term evolution of heat budget in the Mediterranean Sea from Med-CORDEX forced and coupled simulations. Clim Dyn 51:1145-1165. https://doi. org/10.1007/s00382-016-3363-5
Herrmann MJ, Somot S (2008) Relevance of ERA40 dynamical downscaling for modeling deep convection in the Mediterranean Sea. Geophys Res Lett 35:1-5. https://doi.org/10.1029/2007GL032442

IPCC (2013) Climate Change 2013: The Physical Science Basis. Contribution of Working Group I to the Fifth Assessment Report of the Intergovernmental Panel on Climate Change [Stocker TF, Qin D, Plattner G-K, Tignor M, Allen SK, Boschung J, Nauels A, Xia Y, Bex V and Midgley PM (eds)]. Cambridge University Press, Cambridge and New York, pp 1535

IPCC (2018) Global Warming of $1.5^{\circ}$ C.An IPCC Special Report on the impacts of global warming of $1.5^{\circ} \mathrm{C}$ above pre-industrial levels and related global greenhouse gas emission pathways, in the context of strengthening the global response to the threat of climate change, sustainable development, and efforts to eradicate poverty [Masson-Delmotte V,Zhai P, Pörtner H-O, Roberts D, Skea J, Shukla PR, Pirani A, Moufouma-Okia W, Péan C, Pidcock R, Connors S, Matthews JBR, Chen Y, Zhou X, Gomis MI, Lonnoy E, Maycock T, Tignor M, Waterfield T (eds)] (in press)

Jordà G, Marbà N, Duarte CM (2012) Climate warming and Mediterranean seagrass. Nat Clim Change 3:3

Jordà G, Von Schuckmann K, Josey SA et al (2017) The Mediterranean Sea heat and mass budgets: estimates, uncertainties and perspectives. Prog Oceanogr 156:174-208. https://doi.org/10.1016/j. pocean.2017.07.001

Li L, Casado A, Congedi L et al (2012) 7-Modeling of the Mediterranean climate system. In: Lionello P (ed) The climate of the Mediterranean Region. Elsevier, Oxford, pp 419-448

Llasses J, Jordà G, Gomis D et al (2018) Heat and salt redistribution within the Mediterranean Sea in the Med-CORDEX model ensemble. Clim Dyn 51:1119-1143. https://doi.org/10.1007/s0038 2-016-3242-0

L'Hévéder B, Li L, Sevault F, Somot S (2013) Interannual variabilityof deep convection in the Northwestern Mediterranean simulated with a coupled AORCM. Clim Dyn 41(3-4):937-960

Macias D, Garcia-Gorriz E, Stips A (2013) Understanding the causes of recent warming of mediterranean waters. How much could be attributed to climate change? PLoS One. https://doi.org/10.1371/ journal.pone.0081591

Macias DM, Garcia-Gorriz E, Stips A (2015) Productivity changes in the Mediterranean Sea for the twenty-first century in response to changes in the regional atmospheric forcing. Front Mar Sci 2:1-13. https://doi.org/10.3389/fmars.2015.00079

Macias D, Stips A, Garcia-Gorriz E, Dosio A (2018) Hydrological and biogeochemical response of the Mediterranean Sea to freshwater flow changes for the end of the 21stcentury. PLoS One 13:1-16. https://doi.org/10.1371/journal.pone.0192174

Malanotte-Rizzoli P, Artale V, Borzelli-Eusebi GL et al (2014) Physical forcing and physical/biochemical variability of the Mediterranean Sea: a review of unresolved issues and directions for future research. Ocean Sci 10:281-322. https://doi.org/10.5194/ os-10-281-2014

Marbà N, Jordà G, Agustí S, Duarte CM (2016) Evidences of impacts of climate change on Mediterranean Biota. Front Mar Sci 3:1-3. https://doi.org/10.3389/fmars.2016.00003

Mariotti A, Struglia MV, Zeng N, Lau KM (2002) The hydrological cycle in the Mediterranean region and implications for the water budget of the Mediterranean sea. J Clim 15:1674-1690. https://doi.org/10.1175/1520-0442(2002)015\%3c1674:THCIT $\mathrm{M} \% 3 \mathrm{e} 2.0 . \mathrm{CO} ; 2$

Mariotti A, Zeng N, Yoon JH et al (2008) Mediterranean water cycle changes: Transition to drier 21 st century conditions in observations and CMIP3 simulations. Environ Res Lett. https://doi. org/10.1088/1748-9326/3/4/044001

Marshall J, Schott F (1999) Open-ocean convection: observations, theory, and models. Rev Geophys 37:1-64. https://doi. org/10.1029/98RG02739 
Massutí E, Monserrat S, Oliver P et al (2008) The influence of oceanographic scenarios on the population dynamics of demersal resources in the western Mediterranean: hypothesis for hake and red shrimp off Balearic Islands. J Mar Syst 71:421-438. https:// doi.org/10.1016/j.jmarsys.2007.01.009

Meinshausen M, Smith SJ, Calvin K et al (2011) The RCP greenhouse gas concentrations and their extensions from 1765 to 2300 . Clim Change 109:213. https://doi.org/10.1007/s10584-011-0156-z

Millot C (2014) Levantine Intermediate Water characteristics: an astounding general misunderstanding! (addendum). Sci Mar 78:165-171. https://doi.org/10.3989/scimar.04045.30H

Monserrat S, López-Jurado JL, Marcos M (2008) A mesoscale index to describe the regional circulation around the Balearic Islands. J Mar Syst 71:413-420. https://doi.org/10.1016/j.jmars ys.2006.11.012

Nabat P, Somot S, Mallet M et al (2014) Contribution of anthropogenic sulfate aerosols to the changing Euro-Mediterranean climate since 1980. Geophys Res Lett. https://doi.org/10.1002/2014GL0607 98.Abstract

Oddo P, Adani M, Pinardi N et al (2009) A nested Atlantic-Mediterranean Sea general circulation model for operational forecasting. Ocean Sci 5:461-473. https://doi.org/10.5194/os-5-461-2009

Pinardi N, Masetti E (2000) Variability of the large scale general circulation of the Mediterranean Sea from observations and modelling: a review. Palaeogeogr Palaeoclimatol Palaeoecol 158:153-174. https://doi.org/10.1016/S0031-0182(00)00048-1

Robinson AR, Golnaraghi M, Leslie WG et al (1991) The eastern Mediterranean general circulation: features, structure and variability. Dyn Atmos Ocean 15:215-240. https://doi.org/10.1016/03770265(91)90021-7

Roether W, Manca BB, Klein B et al (1996) Recent changes in Eastern Mediterranean deep waters. Science (80-) 271:333-335. https:// doi.org/10.1126/science.271.5247.333

Roether W, Schlitzer R (1991) Eastern Mediterranean deep water renewal on the basis of chlorofluoromethane and tritium data. Dyn Atmos Ocean 15:333-354. https://doi.org/10.1016/03770265(91)90025-B

Ruti PM, Somot S, Giorgi F et al (2015) Med-CORDEX initiative for Mediterranean climate studies. Bull Am Meteorol Soc 97:11871208. https://doi.org/10.1175/bams-d-14-00176.1

Sanchez-Gomez E, Somot S, Mariotti A (2009) Future changes in the Mediterranean water budget projected by an ensemble of regional climate models. Geophys Res Lett 36:1-5. https://doi. org/10.1029/2009GL040120

Sannino G, Carillo A, Pisacane G, Naranjo C (2015) On the relevance of tidal forcing in modelling the Mediterranean thermohaline circulation. Prog Oceanogr 134:304-329. https://doi.org/10.1016/j. pocean.2015.03.002

Sannino G, Herrmann M, Carillo A et al (2009) An eddy-permitting model of the Mediterranean Sea with a two-way grid refinement at the Strait of Gibraltar. Ocean Model 30:56-72. https://doi. org/10.1016/j.ocemod.2009.06.002

Sein DV, Mikolajewicz U, Gröger M et al (2015) Regionally coupled atmosphere-ocean-sea ice-marine biogeochemistry model ROM: 1. Description and validation. J Adv Model Earth Syst 7(1):268-304
Sevault F, Somot S, Alias A et al (2014) A fully coupled Mediterranean regional climate system model: design and evaluation of the ocean component for the 1980-2012 period. Tellus A Dyn Meteorol Oceanogr 66(1):23967

Simoncelli S, Fratianni C, Pinardi N, et al. (2014) Mediterranean Sea physical reanalysis (MEDREA 1987-2015) (Version 1). EU Copernicus Mar Serv Inf. 10.25423/ medsea_reanalysis_phys_006_004.

Skliris N, Lascaratos A (2004) Impacts of the Nile River damming on the thermohaline circulation and water mass characteristics of the Mediterranean Sea. J Mar Syst 52:121-143. https://doi. org/10.1016/j.jmarsys.2004.02.005

Somot S, Houpert L, Sevault F et al (2018a) Characterizing, modelling and understanding the climate variability of the deep water formation in the North-Western Mediterranean Sea. Clim Dyn 51:1179-1210. https://doi.org/10.1007/s00382-016-3295-0

Somot S, Ruti P, Ahrens B et al (2018b) Editorial for the MedCORDEX special issue. Clim Dyn 51:771-777. https://doi. org/10.1007/s00382-018-4325-x

Somot S, Sevault F, Déqué M (2006) Transient climate change scenario simulation of the Mediterranean Sea for the twenty-first century using a high-resolution ocean circulation model. Clim Dyn 27:851-879. https://doi.org/10.1007/s00382-006-0167-z

Somot S, Sevault F, Déqué M, Crépon M (2008) 21st century climate change scenario for the Mediterranean using a coupled atmosphere-ocean regional climate model. Glob Planet Change 63:112126. https://doi.org/10.1016/j.gloplacha.2007.10.003

Soto-Navarro J, Criado-Aldeanueva F, García-Lafuente J, SánchezRomn A (2010) Estimation of the Atlantic inflow through the Strait of Gibraltar from climatological and in situ data. J Geophys Res Ocean. https://doi.org/10.1029/2010JC006302

Soto-Navarro J, Somot S, Sevault F et al (2015) Evaluation of regional ocean circulation models for the Mediterranean Sea at the Strait of Gibraltar: volume transport and thermohaline properties of the outflow. Clim Dyn 44:1277-1292. https://doi.org/10.1007/s0038 2-014-2179-4

Thorpe RB, Bigg GR (2000) Modelling the sensitivity of Mediterranean outflow to anthropogenically forced climate change. Clim Dyn 16:355-368. https://doi.org/10.1007/s003820050333

Waldman R, Brüggemann N, Bosse A et al (2018) Overturning the Mediterranean thermohaline circulation. Geophys Res Lett 45:8407-8415. https://doi.org/10.1029/2018GL078502

Waldman R, Herrmann M, Somot S et al (2017) Impact of the mesoscale dynamics on ocean deep convection: the 2012-2013 case study in the northwestern Mediterranean Sea. J Geophys Res Ocean 122:8813-8840. https://doi.org/10.1002/2016JC012587

Zavatarelli M, Mellor GL (1995) A numerical study of the Mediterranean Sea circulation. J Phys Oceanogr 25:1384-1414. https://doi. org/10.1175/1520-0485(1995)025\%3c1384:ansotm\%3e2.0.co;2

Publisher's Note Springer Nature remains neutral with regard to jurisdictional claims in published maps and institutional affiliations. 


\section{Affiliations}

\section{Javier Soto-Navarro ${ }^{1}$ - G. Jordá ${ }^{2} \cdot$ A. Amores ${ }^{1} \cdot$ W. Cabos $^{3} \cdot$ S. Somot ${ }^{4} \cdot$ F. Sevault ${ }^{4}$. D. Macías ${ }^{5} \cdot$ V. Djurdjevic ${ }^{6}$.} G. Sannino ${ }^{7} \cdot$ L. Li ${ }^{8} \cdot$ D. Sein ${ }^{9,10}$

1 Mediterranean Institute for Advanced Studies (IMEDEA, UIB-CSIC), Mallorca, Spain

2 Spanish Institute of Oceanography (IEO), Mallorca, Spain

3 University of Alcalá de Henares, Alcalá de Henares, Spain

4 Centre National de Recherches Météorologiques (CNRM), Université de Toulouse, Météo-France, CNRS, Toulouse, France

5 European Commission Joint Research Centre (JRC), Ispra, Italy

6 Faculty of Physics, University of Belgrade, Belgrade, Serbia
7 ENEA, Roma, Italy

8 Laboratoire de Météorologie Dynamique (LMD), CNRS, Sorbonne Université, Ecole Normale Supérieure, Ecole Polytechnique, Paris, France

9 Alfred Wegener Institute for Polar and Marine Research, Bremerhaven, Germany

10 Shirshov Institute of Oceanology, Russian Academy of Science, Moscow, Russia 